\title{
GENETIC ANALYSIS OF HYPERTROPHIC CARDIOMYOPATHY PHENOCOPIES
}

$\mathrm{PhD}$ Thesis

Beáta Csányi, MSc

Graduate School of Clinical Medicine

University of Szeged

\author{
Supervisor: \\ Róbert Sepp, MD, PhD \\ 2nd Department of Internal Medicine and Cardiology Center \\ Faculty of Medicine \\ University of Szeged
}

Szeged

2016 


\section{TABLE OF CONTENTS}

LIST OF PUBLICATIONS 4

LIST OF ABBREVIATIONS 5

$\begin{array}{ll}\text { 1. INTRODUCTION } & 7\end{array}$

$\begin{array}{ll}\text { 1.1. Hypertrophic cardiomyopathy } & 7\end{array}$

1.2. Molecular and clinical genetics of hypertrophic cardiomyopathy $\quad 7$

$\begin{array}{ll}\text { 1.3. Hypertrophic cardiomyopathy phenocopies } & 7\end{array}$

1.3.1. Danon disease $\quad 8$

1.3.2. Fabry disease 9

$\begin{array}{ll}\text { 1.3.3. Transthyretin amyloidosis } & 10\end{array}$

$\begin{array}{ll}\text { 2. AIMS } & 13\end{array}$

3. PATIENTS AND METHODS 14

3.1. Patients 14

3.1.1. Screening for mutations in the $L A M P 2$ gene in patients with suspected Danon disease

3.1.2. Screening for mutations in the GLA gene in patients with suspected

$\begin{array}{ll}\text { Fabry disease } & 20\end{array}$

3.1.3. Screening for mutations in the $T T R$ gene in patients with suspected $\begin{array}{ll}\text { transthyretin amyloidosis } & 20\end{array}$

$\begin{array}{ll}3.2 \text { Methods } & 24\end{array}$

3.2.1. Molecular genetic analysis of $L A M P 2, G L A$ and TTR genes $\quad 24$

3.2.2. Restriction fragment analysis of the $L A M P 2$ mutations 24

3.2.3. Bioinformatics 24

3.2.4. Linkage analysis $\quad 24$

4. RESULTS 25

4.1. Identification of $L A M P 2$ mutations in patients with Danon disease 25 
4.1.1. Mutation data

4.1.2. Restriction fragment analysis of the two $L A M P 2$ gene mutations 26

4.1.3. Bioinformatics 26

4.1.4. Genetic screening of Family A and Family B 26

4.1.5 Clinical course of $L A M P 2$ gene mutation carrier family members 26

4.2. Identification of GLA mutations in patients with Fabry disease 28

4.2.1. p.Ile239Met mutation 28

4.2.2. p.Tyr397Stop mutation $\quad 32$

4.2.3. c.548-57_-56dupTA mutation 35

4.2.4. p.Glu358Lys mutation $\quad 35$

4.3. Identification of TTR mutations in patients with transthyretin amyloidosis 35

$\begin{array}{ll}\text { 5. DISCUSSION } & 37\end{array}$

5.1. Identification of $L A M P 2$ mutations in patients with Danon disease $\quad 37$

5.2. Identification of GLA mutations in patients with Fabry disease 39

5.3. Identification of $T T R$ mutations in patients with transthyretin amyloidosis 43

6. SUMMARY AND CONCLUSIONS 46

7. ACKNOWLEDGEMENTS 48

8. REFERENCES 49 


\section{LIST OF PUBLICATIONS}

\section{Publications directly related to the thesis:}

I. Csanyi B, Popoiu A, Hategan L, Hegedus Z, Nagy V, Racz K, Hogye M, Saghy L, Ivanyi B, Csanady M, Forster T, Sepp R. Identification of two novel LAMP2 gene mutations in Danon disease. Can J Cardiol 2016; in press (doi: 10.1016/j.cjca.2016.02.071).

IF: 3,112 (2015)

II. Csányi B, Nagy V, Hategan L, Borbás J, Tringer A, Herczeg B, Forster T, Sepp R. Fabry betegség szürése többszervi érintettséget mutató hipertrófiás cardiomyopathia eseteiben. Cardiologia Hungarica 2016; 46: 158-164.

III. Csányi B, Hategan L, Nagy V, Obál I, Varga ET, Borbás J, Tringer A, Eichler S, Forster T, Rolfs A, Sepp R. Identification of a novel GLA gene mutation, p.Ile239Met, in Fabry disease with a predominant cardiac phenotype. Int Heart J 2016, accepted for publication

IF: 1.938 (2015)

IV. Hategan L, Csányi B, Nagy V, Kis O, Kohári M, Ágoston G, Sághy L, Varga A, Iványi B, Forster T, Sepp R. Transthyretin génmutáció azonosítása hipertrófiás cardiomyopathia képében megjelenő amyloidosisban. Cardiologia Hungarica 2016, nyomtatásban.

Citable abstracts directly related to the thesis:

I. Csányi B, Hategan L, Popoiu A, Rácz K, Hőgye M, Sághy L, Csanády M, Forster T, Sepp R. Danon-betegséget okozó LAMP2 génmutációk azonosítása hypertrophiás cardiomyopathia fenokópiáiban. Identification of LAMP2 gene mutations in Danon disease manifested as phenocopies of hypertrophic cardiomyopathy. Cardiologia Hungarica 2013; 43:B83. 
II. Kanyó É, Popoiu A, Nagy V, Rácz K, Csányi B, Hategan L, Hőgye M, Sághy L, Csanády M, Forster T, Sepp R. Magas mortalitás és gyors progresszió Danon betegségben: három Danon betegségben szenvedő család analízise. Clinical course of Danon disease highlights a highly malignant cardiac disease. Cardiologia Hungarica 2015; 45:D100.

III. Csányi B, Hategan L, Borbás J, Tringer A, Nagy V, Herczeg B, Forster T, Sepp R. Fabry betegség szürése cardiomyopathia fenotípusában jelentkező kardiális kórképek esetén. Screening for Fabry disease in cardiac disorders manifesting as cardiomyopathy phenotypes. Cardiologia Hungarica 2016; 46:F101. 


\section{LIST OF ABBREVIATIONS}

AA: serum amyloid-A amyloidosis

AANF: isolated atrial amyloidosis

ACMG: American College of Medical Genetics and Genomics

ACTC1: alpha-cardiac actin gene

AL: immunoglobulin light-chain amyloidosis

ALP: alkaline phosphatase

AMP: Association for Molecular Pathology

ATTR: familial TTR-linked amyloidosis

$\mathrm{AV}$ : atrioventricular

cDNA: coding deoxyribonucleic acid

CK: creatine kinase

CT: computed tomography

dbSNP: Single Nucleotide Polymorphism Database

DDD: dual-chamber pacemaker

ECG: electrocardiogram

EF: ejection fraction

EMG: electromyography

EP: electrophysiology

Gb3: globotriaosyl-ceramide

$G L A$ : lysosomal $\alpha$-galactosidase A gene

GOT: glutamate oxaloacetate transaminase

GPT: glutamate-pyruvate transaminase

HCM: hypertrophic cardiomyopathy

HGMD: Human Gene Mutation Database

HTX: heart transplantation

ICD: implantable cardioverter defibrillator

LAMP2: lysosome-associated membrane protein-2 gene

LDH: lactic dehydrogenase

LV: left ventricle, left ventricular

LVEDD: left ventricular end-diastolic diameter

LVEF: left ventricular ejection fraction

LVESD: left ventricular end-systolic diameter 
LVmax: maximum left ventricular wall thickness

LVOT: left ventricular outflow tract

MRI: magnetic resonance imaging

$M Y B P C 3$ : myosin binding protein $\mathrm{C}$ gene

MYH7: beta myosin heavy chain gene

MYL2: regulatory myosin light chain gene

MYL3: essential myosin light chain gene

NT-pro-BNP: N-terminal pro B-type natriuretic peptide

NYHA: New York Heart Association

PAS: periodic acid-Schiff

PCR: polymerase chain reaction

PM: pace-maker

PRKAG2: AMP activated protein kinase, $\gamma 2$ regulatory subunit gene

SCD: sudden cardiac death

SLE: systemic lupus erythematosus

SSA: senile systemic amyloidosis

T4: thyroxine

TIA: transient ischemic attack

TNNC1: troponin C gene

TNNI3: troponin I gene

TNNT2: troponin $\mathrm{T}$ gene

TPM1: alpha tropomyosin gene

$T T N$ : titin gene

$T T R$ : transthyretin gene

VAD: ventricular assist device

VUS: variant/mutation of unknown significance

WPW: Wolff-Parkinson-White 


\section{INTRODUCTION}

\subsection{Hypertrophic cardiomyopathy}

Hypertrophic cardiomyopathy (HCM) is a complex and relatively common genetic cardiac disease characterised primarily by unexplained left ventricular hypertrophy [reviewed in detail in (1-4)]. The cavity of the left ventricle is typically narrow. According to current literature data the disease is more frequent, then it was previously thought as its prevalence was shown to be 1/500-1000 (5). The clinical phenotype is heterogeneous and clinically the patients may be asymptomatic, but the development of symptoms in form of dyspnea, chest pain, palpitation or syncope is more typical. HCM is an important cause of disability and death in patients of all ages, although sudden and unexpected death in young people is perhaps the most devastating component of its natural history. The overall risk of diseaserelated complications such as sudden death, end-stage heart failure, and fatal stroke is roughly $1-2 \%$ per year, but the absolute risk in individuals varies as a function of underlying genetic abnormality, age, myocardial pathology, and other pathophysiological abnormalities such as impaired peripheral vascular responses.

\subsection{Molecular and clinical genetics of hypertrophic cardiomyopathy}

Hypertrophic cardiomyopathy is an autosomal dominant inherited genetic disorder with variable expression and penetrance. Using molecular genetic methods specific alterations in genes encoding for mainly sarcomere proteins were found to cause the disease in approximately $60 \%$ of individuals with HCM [Table 1, reviewed in detail in $(6,7)]$. The most important affected genes implicated in the disease include the beta myosin heavy chain- (MYH7) (8), the alpha tropomyosin- (TPM1) (9), the troponin T- (TNNT2) (9), the myosin binding protein C- (MYBPC3) $(10,11)$, the troponin I- (TNNI3) (12), the essential(MYL3) and the regulatory myosin light chain- (MYL2) (13), the alpha-cardiac actin(ACTC1) (14) and the titin (TTN) genes (15).

\subsection{Hypertrophic cardiomyopathy phenocopies}

Mutations affecting sarcomere genes are present in 40-60\% of HCM patients. In 5-10\% of the cases mutations affect genes which may lead to HCM phenocopies, i.e. diseases that mimic HCM but are caused by other etiologies capable of producing myocardial hypertrophy (e.g. Fabry disease, Danon disease, transthyretin amyloidosis, etc.) (16). In the remaining $20-25 \%$ of the cases the cause of HCM is still unknown. Some of the inherited syndromes, as well as metabolic and mitochondrial disorders, can present as clinical 


\begin{tabular}{|c|c|c|c|}
\hline Gene & Symbol & Locus & Prevalence (\%) \\
\hline beta myosin heavy chain & $M Y H 7$ & $14 \mathrm{q} 12$ & $15-25$ \\
\hline myosin binding protein C & $M Y B P C 3$ & $11 \mathrm{p} 11.2$ & $15-25$ \\
\hline troponin T & $T N N T 2$ & $1 \mathrm{q} 32$ & $<5$ \\
\hline troponin I & $T N N I 3$ & $19 \mathrm{q} 13.4$ & $<5$ \\
\hline troponin C & $T N N C 1$ & $3 \mathrm{p} 21-\mathrm{p} 14$ & $<1$ \\
\hline alpha-tropomyosin & $T P M 1$ & $15 \mathrm{q} 22$ & $<5$ \\
\hline alpha cardiac actin & $A C T C 1$ & $15 \mathrm{q} 14$ & $<1$ \\
\hline essential myosin light chain & $M Y L 3$ & $3 \mathrm{p} 21.31$ & $<1$ \\
\hline regulatory myosin light chain & $M Y L 2$ & $12 \mathrm{q} 24.21$ & $<2$ \\
\hline titin & $T T N$ & $2 \mathrm{q} 31$ & $<1$ \\
\hline $\begin{array}{c}\text { AMP activated protein kinase, } \gamma 2 \\
\text { regulatory subunit }\end{array}$ & PRKAG2 & $7 \mathrm{q} 34-\mathrm{q} 36$ & $<1$ \\
\hline
\end{tabular}

Table 1. Affected sarcomere genes and their prevalence in hypertrophic cardiomyopathy.

phenocopies and can be distinguished by their associated cardiac and noncardiac features and on the basis of their unique molecular genetics. The mode of inheritance, natural history and treatment of phenocopies can differ from those of HCM caused by mutations in sarcomere genes. Detailed clinical evaluation and mutation analysis are, therefore, important in providing an accurate diagnosis in order to enable genetic counseling, prognostic evaluation and appropriate clinical management.

\subsubsection{Danon disease}

Danon disease (OMIM\# 300257) is a rare X-linked dominant disorder characterised by cardiomyopathy, skeletal myopathy, and mental retardation. In 1981, Moris J. Danon and colleagues reported two unrelated boys first with the clinical triad (17). Since then, there have been a number of additional case reports in the English literature. While skeletal myopathy is generally mild and the mental retardation variable, it is hypertrophic cardiomyopathy which dominates the clinical picture with intracytoplasmic vacuoles containing autophagic material and glycogen in skeletal and cardiac muscle cells and determines the outcome. Cardiac symptoms in male carriers usually begin during adolescence, and patients die of heart failure in their third decade. In contrast, skeletal myopathy is usually mild, weakness and atrophy predominantly affect shoulder girdle and neck muscles, but distal muscles may also be involved. Women are less severely affected than men, with disease onset in late adulthood and with slower progression (18). Women 
tend to exhibit a dilated rather than a hypertrophic cardiomyopathy (19). The distal skeletal muscles are less commonly affected in men (18). Mild mental retardation and hepatomegaly are reported in $70 \%$ of male patients and $36 \%$ of female patients, respectively (20). Blood creatine kinase (CK) levels are usually elevated (ranging from 300-3,000 U/L). Myopathic motor unit changes and, occasionally, abnormal spontaneous activity has been described on electromyographic examination (20).

Danon disease is caused by the primary deficiency of lysosome-associated membrane protein-2 (LAMP-2). Inheritance of Danon disease has been considered to be X-linked dominant because in most familial cases males are affected predominantly, affected mothers usually have milder and later-onset cardiac symptoms, and no male-to-male transmission has been described.

The LAMP2 gene is located on the chromosome region Xq24. The LAMP-2 protein structurally consists of a small cytoplasmic tail with a lysosomal membrane targeting signal, a transmembrane domain, and a large intraluminal head with two internally homologous domains connected by a hinge region rich in proline, serine or threonine each domain contains four cysteine residues that form two disulphide bonds (21). LAMP-2 proteins coat the inner surface of the lysosomal membrane (mainly LAMP-2B isoform) and are also abundant on the plasma membrane (mainly LAMP-2A and LAMP-2C isoforms) (22). The LAMP2 open reading frame consists of 1,233 nucleotides and encodes 410 amino acids. Exons 1-8 and part of exon 9 encode the luminal domain; the remainder of exon 9 encodes both the transmembrane domain and the cytoplasmic domain. Alternative splicing close to the three primed end of the primary transcript generates three isoforms which differs in the transmembrane and cytoplasmic domains (23).

The molecular diagnosis of Danon disease has so far been based on the demonstration of LAMP-2 protein deficiency in skeletal or cardiac muscle and/or the identification for LAMP2 gene mutations. However, because of the rarity of the disease, clinical knowledge is relatively scarce with regard to phenotypic manifestation of the disease and therefore any additional clinical information is of value.

\subsubsection{Fabry disease}

Fabry disease (FD, OMIM\# 301500) is a rare X-linked recessive disorder caused by mutations in the GLA gene (OMIM\# 300644), encoding a lysosomal hydrolase enzyme, $\alpha$ galactosidase A [ $\alpha$-gal A; GLA; EC 3.2.1.22, reviewed in detail in (24)]. Mutations 
affecting the GLA gene and enzyme will result in the accumulation of complex sphingolipids, mainly globotriaosyl-ceramide (Gb3) in the lysosome, which subsequently will lead to Fabry disease, a systemic disorder with multiple organ involvement. In the hemizygous patients, symptoms are typically first experienced in early childhood, consisting of acroparesthesia, abdominal pain and fever. During adolescence, the affected subjects may exhibit angiokeratomas, hypohidrosis, proteinuria, progressive renal insufficiency and cornea verticillata. Progressing with age, patients may manifest cardiomyopathy, arrhythmia and cerebrovascular complications in the fourth decade (24). Cardiac involvement as left ventricular hypertrophy, hypertrophic cardiomyopathy and conduction disturbances are detected in $60 \%$ of Fabry patients. The most common causes of death are renal failure, heart failure and/or heart attack, myocardial infarction and stroke caused by the deposited and accumulated lipid degradation products, the globotriaosylceramide in the vessels.

The human lysosomal $\alpha$-galactosidase A enzyme is encoded by an unique gene, GLA (OMIM\#300644), located on the long arm of chromosome X (Xq21.3-q22). The major transcript of GLA gene consists of six introns and seven exons comprising 1318 base pairs (bp). It encodes a homodimeric glycoprotein composed of 429 amino acids. The major function of the enzyme is to hydrolyse the molecular parts of terminal alpha-galactosile from glycolipids and glycoproteins. Pathological changes in GLA - both the gene and its encoded protein — result in storage of complex sphingolipids in the lysosome, mainly globotriaosyl-ceramide, which in turn causes Fabry disease. Currently 664 GLA gene mutations are known in the literature, which may be associated with the development of Fabry disease. There is extensive allelic heterogeneity, but no genetic locus heterogeneity in the disease.

According to the degree of enzyme deficiency the disease can clinically manifest in 3 different forms. Homozygous males do not show any $\alpha$-galactosidase activity in the plasma, leading to the manifestation of the classical form of Fabry disease. If low $\alpha$ galactosidase enzyme activity is observed in the homozygous males (5-35\% of the normal activity), the disease can manifest in an atypical form. Probably this is the most common variant. Heterozygous females can present very variable enzyme levels (0-100\%) and clinical manifestations due to random X-chromosome inactivation (25). 


\subsubsection{Transthyretin amyloidosis}

Amyloidoses are a group of diseases which are caused by extracellular deposition of morphologically indistinguishable materials, called amyloid. In approximately 95\%, amyloid consists of fibrils formed by aggregation of misfolded insoluble proteins, the remaining 5\% being the $\mathrm{P}$ component (pentameric protein, member of the pentraxins family of serum proteins) and other glycoproteins such as proteoglycans and sulfated glycosaminoglycans. Under the light microscope the amyloid appears as an eosinophilic amorphous substance in hematoxylin - eosin stained sections. Amyloid binds Congo red dye and, when stained, produces apple-green birefringence under polarised light, which is used as "gold" standard for diagnosis (26).

The precursor protein may be present in an abnormal form and quantity in the serum. It is unclear what makes these proteins amyloidogenic. Amyloid deposition can affect a variety of tissues, organs, most commonly the kidneys, liver, heart, autonomic nervous system, either multiple or isolated organs of the body. Clinical signs arise from the damaged function of the infiltrated organs and highly depends on the degree of involvement. According to statistics derived from autopsy series the prevalence of the disease is 0.5$2.2 \%$

The involvement of the heart is the most common in all three form of amyloidosis (Table 2). Immunoglobulin light chain deposition occurs in AL amyloidosis. Wild-type transthyretin protein accumulates in SSA (senile systemic amyloidosis) amyloidosis, while mutant transthyretin protein is deposited in ATTR amyloidosis (27). In addition to the above, serum-amyloid-A amyloidosis (AA) and isolated atrial amyloidosis (AANF) forms further groups $(28,29)$.

Familial TTR-linked amyloidosis (ATTR) is an autosomal dominant genetic disorder with incomplete penetrance, caused by mutations in the transthyretin gene (TTR) encoding transthyretin protein (30). The gene for human transthyretin (TTR; MIM\# 176300) maps to chromosome 18 (18q12.1). The major transcript of TTR gene consists of 3 introns and 4 exons comprising 957 base pairs (bp). It encodes a homotetrameric transthyretin protein of 147 amino acids. Transthyretin is a $55 \mathrm{kDa}$ homotetramer transport protein in the serum and cerebrospinal fluid that carries the thyroid hormone thyroxine (T4) and retinol-binding protein bound to retinol. The liver secretes transthyretin into the blood, and the choroid plexus secretes TTR into the cerebrospinal fluid. TTR has a 'dimer of dimers' quaternary structure. Each TTR monomer is a 127-residue polypeptide rich in beta sheet structure. 


\begin{tabular}{|l|l|l|l|}
\hline Type & Precursor protein & Site of synthesis & Organ manifestation \\
\hline AL & $\begin{array}{l}\text { light chain kappa or } \\
\text { lambda }\end{array}$ & bone marrow & $\begin{array}{l}\text { kidney, heart, gastrointestinal } \\
\text { tract, liver, nervous system, soft } \\
\text { tissue }\end{array}$ \\
\hline ATTR & mutant transthyretin & liver & nervous system, heart \\
\hline SSA & wild type transthyretin & liver & heart \\
\hline AA & serum amyloid A & liver & $\begin{array}{l}\text { kidney, gastrointestinal tract, } \\
\text { liver, nervous system, spleen } \\
\text { (rarely heart) }\end{array}$ \\
\hline AANF & atrial natriuretic peptide & atrium & atrium \\
\hline
\end{tabular}

Table 2. Main forms of systemic amyloidosis affecting the heart

Association of two monomers via their beta-strands forms an extended beta sandwich. Further association of two of these dimers in a face-to-face fashion produces the homotetrameric structure and creates the two thyroxine binding sites per tetramer. This dimer-dimer interface, comprising the two T4 binding sites, is the weaker dimer-dimer interface and is the one that comes apart first in the process of tetramer dissociation.

In SSA the deposition of wild type transthyretin leads to symptoms typically at age of 7080 years, while in hereditary amyloidosis the disease usually manifests around age of 60 years. Transthyretin amyloidosis typically affects two organ systems, therefore the disease leads to two main phenotypes: in familial amyloid polyneuropathy the phenotype is dominated by neuropathy, while in familial cardiac amyloidosis cardiomyopathy predominates. However, considerable overlap exists between the two major phenotypes. Besides the two main forms, oculo-meningeal forms of the disease are also known (30). 


\section{AIMS}

Previous to our work, no information was available with regard to the occurrence of HCM phenocopies in Hungarian patients with hypertrophic cardiomyopathy. As HCM phenocopies substantially differ from those of HCM caused by sarcomeric mutations with regard to genetic counseling, prognostic evaluation and appropriate clinical management, their accurate diagnosis by detailed clinical evaluation and mutation analysis is of great clinical importance. Therefore, our aim was to screen HCM patients with suspected multisystem symptoms suggesting HCM phenocopies.

In my $\mathrm{PhD}$ work I aimed to:

1. Identify mutations affecting the lysosome-associated membrane protein-2 (LAMP2) gene in patients with suspected Danon disease;

2. Identify mutations affecting the $\alpha$-galactosidase $\mathrm{A}(G L A)$ gene in patients with suspected Fabry disease;

3. Identify mutations affecting the transthyretin $(T T R)$ gene in patients with suspected transthyretin amyloidosis;

4. Conduct clinical and genetic screening of family members of patients with $L A M P 2$, GLA and TTR gene mutations. 


\section{PATIENTS AND METHODS}

\subsection{Patients}

Patients with the suspicion of HCM phenocopies were analyzed. In all cases collection of case history data, physical examination, overview of available clinical documentation, 12 lead ECG and transthoracic echocardiography were carried out. In selected cases patients were hospitalised for detailed in-hospital cardiology assessment (24-hour Holter monitoring, stress test, semi-supine bicycle stress echocardiography, cardiac MRI, coronarography, haemodynamic study). In all cases the diagnosis of HCM was based on internationally accepted diagnostic criteria (2-4).

\subsubsection{Screening for mutations in the $L A M P 2$ gene in patients with suspected Danon disease}

We analysed two unrelated patients and their families with HCM morphology and the suspicion of Danon disease.

\section{Family A}

In Family A, the index patient, a Rumanian boy (Figure 1, subject III:1 in Family A), came to medical attention at the age of 12 years because of a heart murmur. His ECG (Figure 2, Panel A) showed a sinus rhythm with a short PR interval and a wide QRS complex with delta waves resembling the Wolff-Parkinson-White (WPW) pattern. Echocardiography revealed massive asymmetric left ventricular (LV) hypertrophy, predominantly of the free wall (interventricular septum thickness: $30 \mathrm{~mm}$, and LV free wall thickness: $39 \mathrm{~mm}$ ), preserved LV ejection fraction (LVEF: 64\%), systolic anterior movement of the mitral valve, severe obstruction of the LV outflow tract (LVOT) with a peak systolic gradient of $178 \mathrm{mmHg}$ and severe mitral insufficiency (Figure 2, Panel $C$ and Table 3). The hypertrophy involved the right ventricle, too.

At the age of 14 years, progressive muscle weakness developed. The clinical assessment showed an asthenic body constitution (body mass index: 16.14) and proximal atrophy of the scapulohumeral muscles. He had a moderate mental retardation with an IQ of 48 (Raven scale) and affective and cognitive immaturity. The neurological findings revealed a proximal motor deficit, severe muscular atrophy with deltoid and triceps pseudohypertrophy, bilateral talus varus and osteotendinous hyporeflexia. The laboratory findings indicated elevated levels of transaminases [GPT: $183 \mathrm{U} / 1$ (normal range: 2-41 U/l), GOT: 376 U/L (normal range: 2-38 U/1)], creatine phosphokinase (CK): 1236 UI/1 
(normal range: 24-270 U/L), and lactic dehydrogenase (LDH): 833 U/l (normal range: 40$300 \mathrm{U} / \mathrm{l})$. On the basis of the above findings, limb-girdle muscular dystrophy was diagnosed.

At the age of 15 years, still with preserved LV function (LVEF: 62\%), an implantable cardioverter defibrillator (ICD) was implanted as primary prophylaxis for sudden cardiac death (SCD) according to recent guidelines $(2,3)$. Three years later, the patient presented several episodes of atrial flutter, with variable 3:1, 4:1, 6:1 AV block, responding to cardioversion. In the last year of his 11-year-long follow-up, the proband (now 23 years old) progressed into a dilated phase, exhibiting left ventricular dilatation (LVEDD raised from $30 \mathrm{~mm}$ to $41 \mathrm{~mm}$ ) and a decrease of the LVEF from $64 \%$ to $35 \%$. There is also echocardiographic evidence of thrombi in the left atrium and ventricle, and because of this oral anticoagulant treatment was started. The patient has chronic atrial fibrillation with a low ventricular response rate of 61 beats/minute.

Family screening revealed a rich family history. The maternal grandmother (Figure 1, subject I:2 in Family A) had a non-obstructive hypertrophic cardiomyopathy, heart failure of New York Heart Association (NYHA) functional class III and chronic atrial fibrillation. A VVI pacemaker was implanted at the age of 44 years as antibradycardia protection. Death occurred at 60 years because of heart failure. The mother of the index patient (Figure 1, subject II:1 in Family A) has ECG changes with negative T waves in V4-V6, but no clinical signs of Danon disease. The maternal half-brother (Figure 1, subject III:6 in Family A) was diagnosed with hypertrophic non-obstructive cardiomyopathy, muscular dystrophy (elevated transaminases GOT: 360 U/1, GPT: 373 U/1, CK: 1739 U/1, CK-MB: 11,7 ng/ml, and LDH: $1004 \mathrm{U} / \mathrm{l}$ ) at 20 years of age. At the age of 25 years, ICD implantation was performed for the primary prevention of SCD and for atrial fibrillation with low ventricular response rates of 24-36 beats/minute. At 29 years of age, he died as a consequence of progression to severe heart failure and stroke. An uncle of the index patient (Figure 1, subject II:3 in Family A) was diagnosed with non-obstructive cardiomyopathy, atrial fibrillation, heart failure, and later third degree AV block at the age of 23 years. He received a pacemaker, and died at the age of 34 years. An aunt of the index patient (Figure 1, subject II:6 in Family A) was diagnosed with non-obstructive hypertrophic cardiomyopathy at the age of 18 years. Six years later, atrial fibrillation, LBBB and severe heart failure with LV dilatation and decreased LVEF (LVEDD: $59 \mathrm{~mm}$, 
and LVEF: 25\%) occurred. A DDD pacemaker implantation was proposed, but she died suddenly.

The cousin of the index patient (Figure 1, subject III:5 in Family A) presented with obstructive hypertrophic cardiomyopathy, mental retardation and muscular dystrophy of limb-girdle type at the age of 13 years. His echo findings included severe LV hypertrophy, more pronounced at the free wall than at the septum (interventricular septum thickness: 25 $\mathrm{mm}$, and LV free wall thickness: $40 \mathrm{~mm}$ ), and LV outflow tract obstruction with a gradient of $57 \mathrm{mmHg}$ (Figure 2, Panel D and Table 1). His laboratory findings also showed increased levels of transaminases, CK and LDH (GOT: 234 U/1, GPT: 360 U/1, LDH: 1254 U/l, and CK: $1329 \mathrm{U} / \mathrm{l}$ ). An MRI assessment confirmed the massive LV hypertrophy (LV free wall: $42.3 \mathrm{~mm}$ and interventricular septum: $30 \mathrm{~mm}$; Figure 2, Panel $E$ and F). Late gadolinium enhancement revealed focal changes in the basal and apical septum, and also in the free wall of the LV. In the last year of his 4-year-long follow-up, progression into a dilated phase was observed with systolic dysfunction (LVEDD increased from $25 \mathrm{~mm}$ to $56 \mathrm{~mm}$, and LVEF decreased from $88 \%$ to $45 \%$ ).

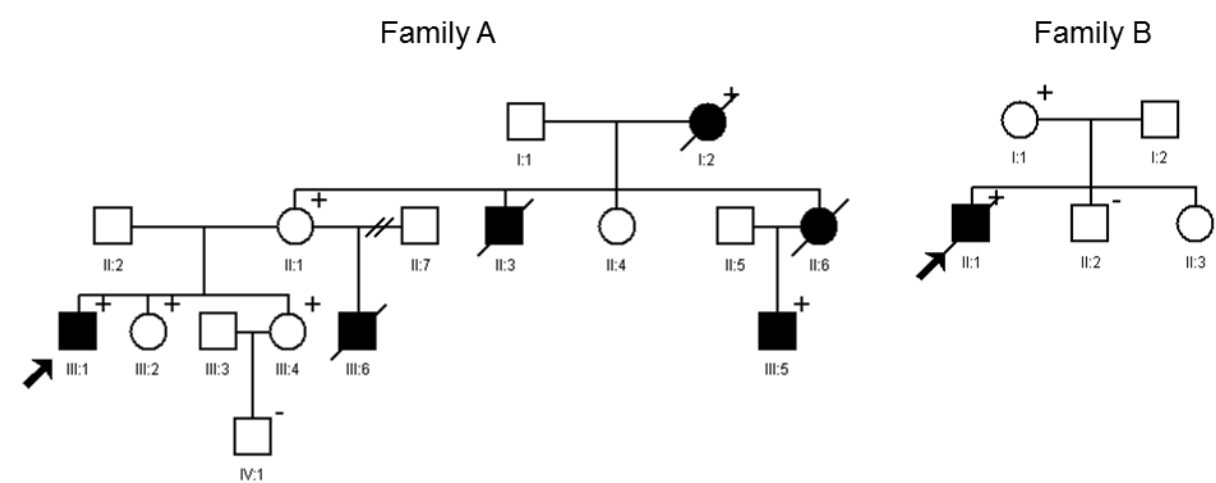

Figure 1. Pedigrees of the LAMP2 gene mutation carrier Family A and Family B. Squares and circles denote males or females, respectively; filled symbols represent clinically affected family members. Arrow points to the index patients. Deceased individuals are slashed. Mutation carriers are labelled with a plus (+) sign, non-carriers with a minus (-) sign.

\section{Family $B$}

In Family B, the index patient was a Hungarian boy (Figure 1, subject II:1 in Family B), who was first admitted at the age of 14 years because of exercise-induced tachycardia. ECG showed a sinus rhythm, a short PR interval and left ventricular hypertrophy. Echocardiography revealed non-obstructive hypertrophic cardiomyopathy with a LV wall thickness of $16 \mathrm{~mm}$ and a normal LV ejection fraction (LVEF: 73\%). The laboratory 
findings included elevated enzyme levels (CK: $729 \mathrm{U} / 1$ and LDH: $1149 \mathrm{U} / \mathrm{l})$, with a normal CK MB fraction (41 U/1, 5.6\%) and elevated transaminases (GOT: 240 U/1 and GPT: 190 $\mathrm{U} / \mathrm{l})$.

On follow-up, elevated CK levels persisted in the range 650-1200 U/l, with normal MB fraction and troponin levels, but signs or symptoms of muscle wasting or weakness did not develop. Follow-up echocardiography recorded an increase in LV wall thickness (LV wall diameter 26-28 mm). Audiometry revealed a left-sided mild neural hearing loss; the ophthalmology was normal. Mild mental retardation was present.

At the age of 15 years, cardiac arrest occurred on mild exercise, due to ventricular fibrillation (the first recorded rhythm in the ambulance), which was successfully defibrillated. For secondary prevention, a DDD ICD was implanted. After ICD implantation, an inappropriate ICD discharge occurred because of supraventricular tachycardia. An EP study was performed which revealed a concealed septal-parahisian accessory pathway and an inducible orthodromic AV tachycardia under isuprel infusion. Non-sustained atrial tachycardia was also induced. Ablation of the accessory pathway was attempted, and proved successful, but a second ablation was necessary three years later, after multiple episodes of ICD inappropriate discharges induced by supraventricular tachycardia. A detailed EP study was again performed and a second accessory pathway was eliminated successfully at the anterior segment of the mitral ring.

At the age of 19 years LV dilatation was noted (LVEDD: $46 \mathrm{~mm}$ and LVESD: $37 \mathrm{~mm}$ ) with a mild decrease in EF (EF: 44-48\%), and the patient was evaluated for heart transplantation. On oxy-spiroergometry, the aerobic capacity was measured as 14.2 $\mathrm{ml} / \mathrm{kg} / \mathrm{min}$. In a 6-min walk test, he walked for $330 \mathrm{~m}$ without desaturation. An endomyocardial biopsy was also performed, which showed severe cardiomyocyte hypertrophy with extensive sarcoplasmic vacuolisation compatible with Danon disease (Figure 3, Panel A-D).

Four months later, at the age of 20 years, left-sided hemiparesis occurred due to an acute ischemic stroke, which showed spontaneous regression without thrombolysis. Soon after, bi-ventricular heart failure and low-output syndrome developed, aggravated by bronchopneumonia, and the patient died because of intractable heart failure. The last echocardiography showed an LVEDD of $61 \mathrm{~mm}$, and LVESD of $49 \mathrm{~mm}$, and an EF of $40 \%$. 
The mother of the index patient (Figure 1, subject I:1 in Family B) was first assessed at the age of 44 years when she exhibited normal echocardiography parameters (interventricular septum: $10 \mathrm{~mm}$, LV free wall: $10 \mathrm{~mm}$, LVEDD: $47 \mathrm{~mm}$, LVESD: $31 \mathrm{~mm}$ and EF: 63\%). An ECG showed a sinus rhythm of 44/min with biphasic T waves in V2-3. After having two syncopal episodes at the age of 48 years, atrial tachycardia and a junctional escape rhythm were found, leading to the performance of an EP study. This
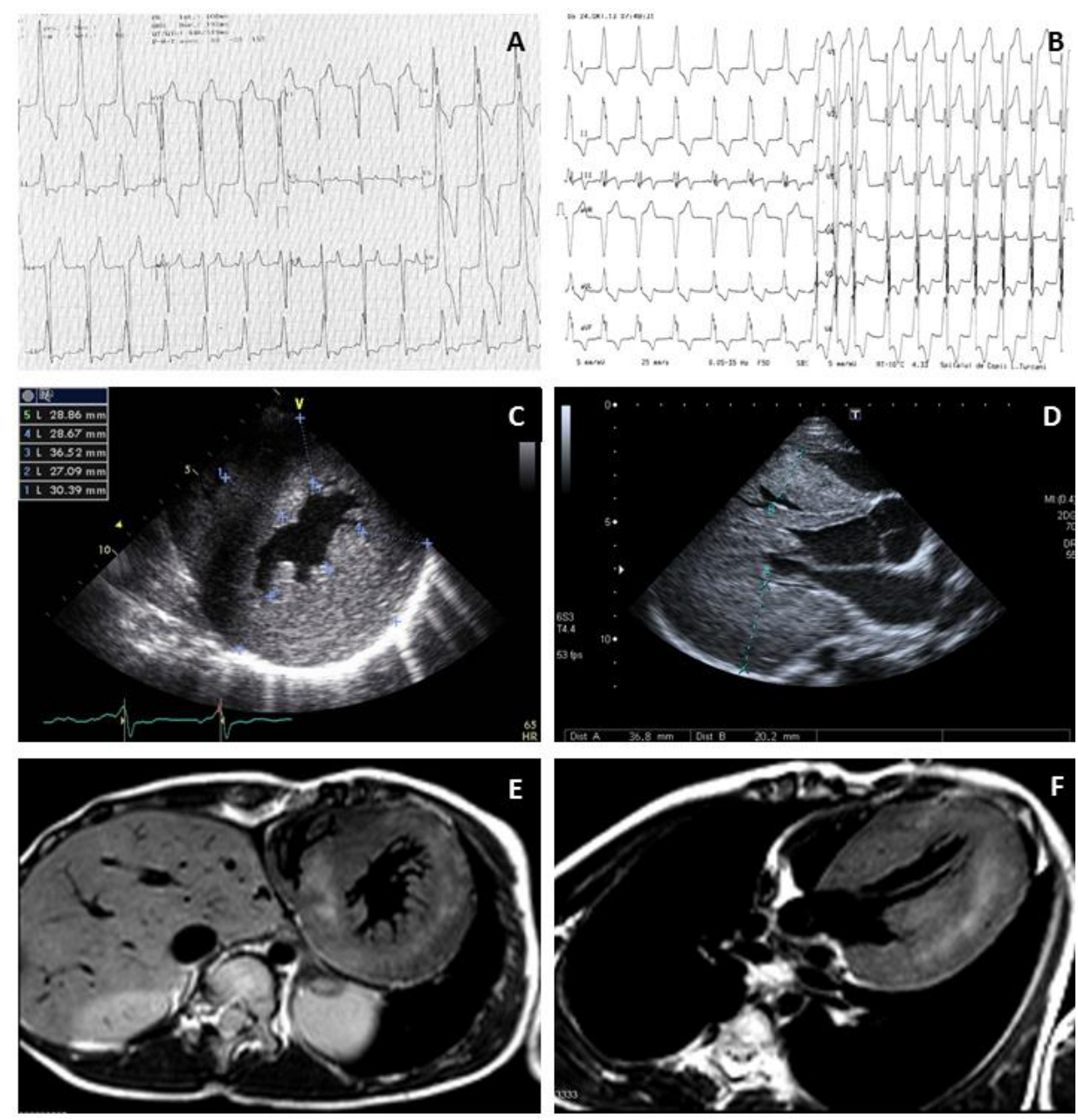

Figure 2. ECG and morphological appearance of Danon disease. 12-lead resting ECG of the index patient in Family A (subject III:1, Family A; Panel A) and his cousin (subject III:5, Family A; Panel B) showing sinus rythm, left axis, short $P Q$ interval, and delta waves in leads I, aVL, and V4-6, resembling Wolff-Parkinson-

White syndrome. Paper speed $25 \mathrm{~mm} / \mathrm{s}$, calibration $5 \mathrm{~mm} / \mathrm{mV}$. Panel C: Parasternal short axis view of transthoracic echocardiography of the index patient of Family A (subject III:1, Family A) showing extreme concentric left ventricular hypertrophy, with left ventricular wall thickness of 27-36 mm, predominating at the left ventricular free wall. Panel D: Parasternal long axis view of transthoracic echocardiography of the cousin of the index patient (subject III:5, Family A), showing extreme concentric left ventricular hypertrophy, with left ventricular wall thickness of 20-36 mm, predominating at the left ventricular free wall. Panel E and F: Cardiac magnetic resonance imaging of the cousin of the index patient (subject III:5, Family A), showing massive hypertrophy of the left ventricle ( $L V$ free wall: $42.3 \mathrm{~mm}$, interventricular septum: $30 \mathrm{~mm}$ ) with late gadolinium enhancement revealing focal changes in the basal and apical septum, as well as in the free wall of the left ventricle. 
study showed multiple atrial tachycardias (ATs) with divergent mechanisms and localisations. Altogether 3 different ATs were inducible and two of these tachycardias were ablated successfully (one right atrial cavotricuspidal-isthmus-dependent flutter and another focal left atrial tachycardia with a posterolateral origin). The most likely mechanism of the third tachycardia was a macro-reentry, propagating around the left atrial appendage, but this arrhythmia was not mappable completely because of spontaneous termination.

The younger brother of the index patient (Figure 1, subject II:2 in Family B) had no symptoms at the age of 12 years, and exhibited normal ECG and echocardiography.
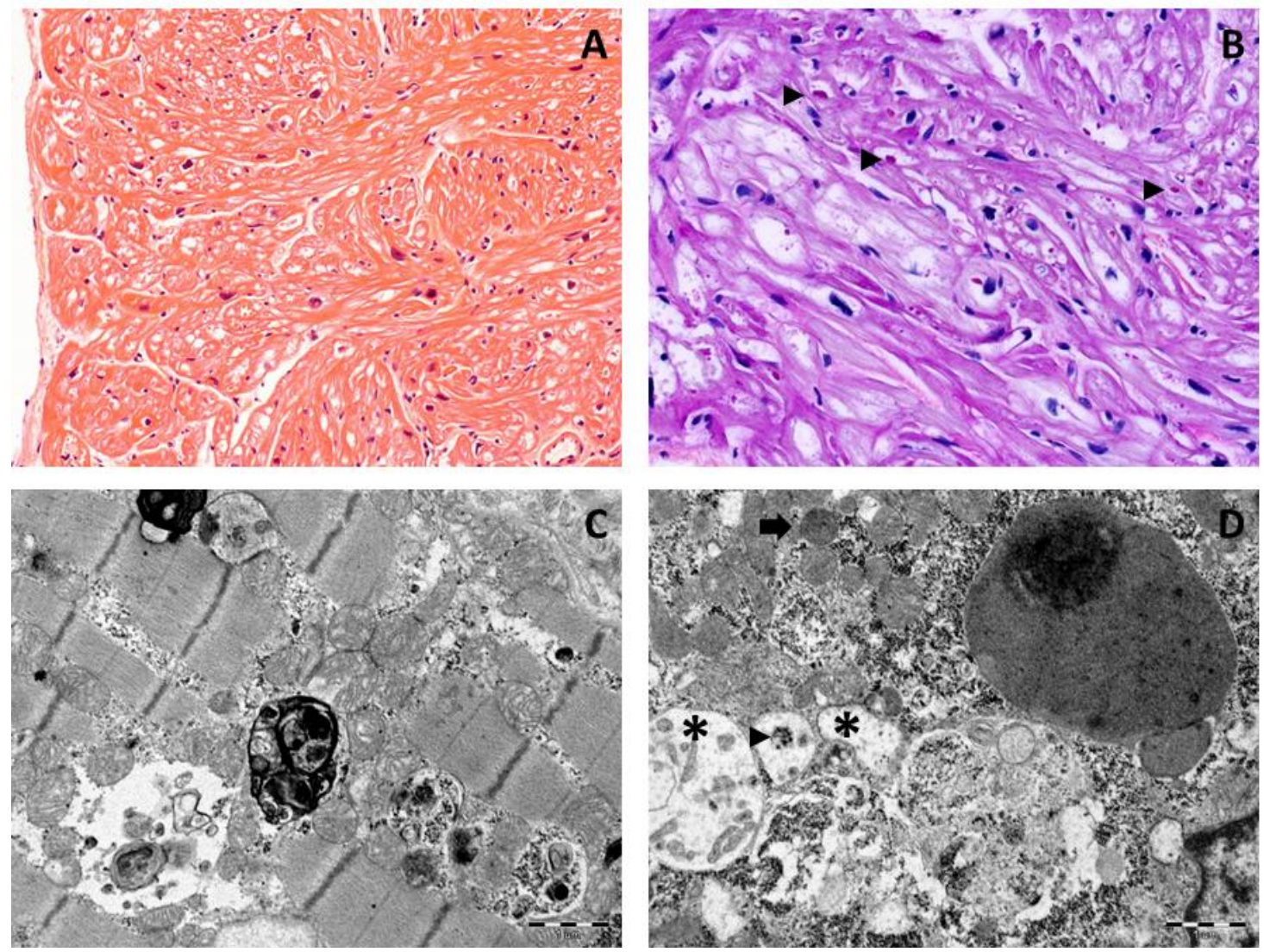

Figure 3. Histology of LAMP2 vacuolar cardiomyopathy. Panel A: Hypertrophied cardiomyocytes with myofiber disarray and sarcoplasmic vacuolisation. Hematoxylin-eosin; original magnification x20. Panel B.

PAS-positive (proved diastase-resistant) sarcoplasmic inclusions (arrowheads), irregular widespread sarcoplasmic vacuolisation, and marked hypertrophy of the cardiomyocytes. Sarcoplasmic glycogen content seems not to be increased. Periodic acid-Schiff, original magnification x40. Panel C: Autophagic vacuoles among myofibrils, with disrupted limiting membranes. Electron microscopy, original magnification $x 7500$. Bar represents $1 \mu \mathrm{m}$. Panel D: Perinuclearly located autophagic vacuoles (asterisks), with discontinuous

limiting membranes. The vacuoles contain glycogen particles (arrowhead) and degenerated cellular membranes. The autolysosome filled with dense material (arrow) corresponds to the PAS-positive inclusions shown in Panel B. Bar represents $1 \mu \mathrm{m}$. 


\subsubsection{Screening for mutations in the $G L A$ gene in patients with suspected Fabry disease}

A total of 21 patients (14 women, 7 men; mean age $52 \pm 13$ years), with suspected Fabry disease, underwent screening. Cardiac involvement was present in 18 cases as hypertrophic cardiomyopathy ( 9 women, 4 men; mean age $46 \pm 14$ years) or left ventricular hypertrophy ( 1 woman, 4 men; mean age $60 \pm 7$ years); while restrictive and dilated cardiomyopathy, one case each, was also included. In one case the diagnosis of cornea verticillata indicated the screening. Non-cardiac signs included neurological, renal, ocular or dermatological symptoms. During the screening protocol genetic analysis of the coding regions of the GLA gene was performed. In all cases the diagnosis of cardiomyopathies was based on internationally accepted diagnostic criteria (2-4). Non-cardiac manifestation included neurological symptoms in 9 cases (cerebrovascular insult, transient ischemic attack, acroparesthesia and white matter damage confirmed by CT), renal symptoms in 6 cases (proteinuria, nephropathy, renal failure), ocular symptoms in 2 cases (cornea verticillata, retinal dystrophy), dermatological symptoms in 2 cases and other, not HCM-specific cardiac symptoms in 3 cases ( 3 rd degree AV block, marked restrictive physiology with the exclusion of amyloidosis). Family screening was available in two cases.

\subsubsection{Screening for mutations in the $T T R$ gene in patients with suspected transthyretin amyloidosis}

We analysed two unrelated patients with HCM morphology and the suspicion of transthyretin amyloidosis.

\section{Patient A}

Past medical history of the 60-years-old male patient included hypertension. Four years before presentation carpal tunnel syndrome was detected with EMG which was initiated because of bilateral hand numbness necessitating operation. Laboratory findings revealed elevated liver function (ALP, GGT). Cardiac assessment was initiated because of effort dyspnea, angina pectoris and presyncope. His ECG showed 43-53/min bradycardia, due to II-III degree AV block. Echocardiography indicated enlarged left $(61 \times 65 \times 69 \mathrm{~mm})$ and right atria, concentric left ventricular (LV) hypertrophy (interventricular septum thickness: $27 \mathrm{~mm}$, left ventricle posterior wall thickness: $21 \mathrm{~mm}$; Figure 4, Panel A and B), normal LV diameters, diffuse hypokinesia, mildly decreased ejection fraction (EF 48\%), 2nd degree mitral- and tricuspidal regurgitation with restrictive diastolic dysfunction (E/A: 
114/34, DCT: 118 ms, Ea: 6, E/Ea: 19). NT-pro-BNP (3511 pg/ml) and troponin T (0,042 ug/l) levels were elevated.
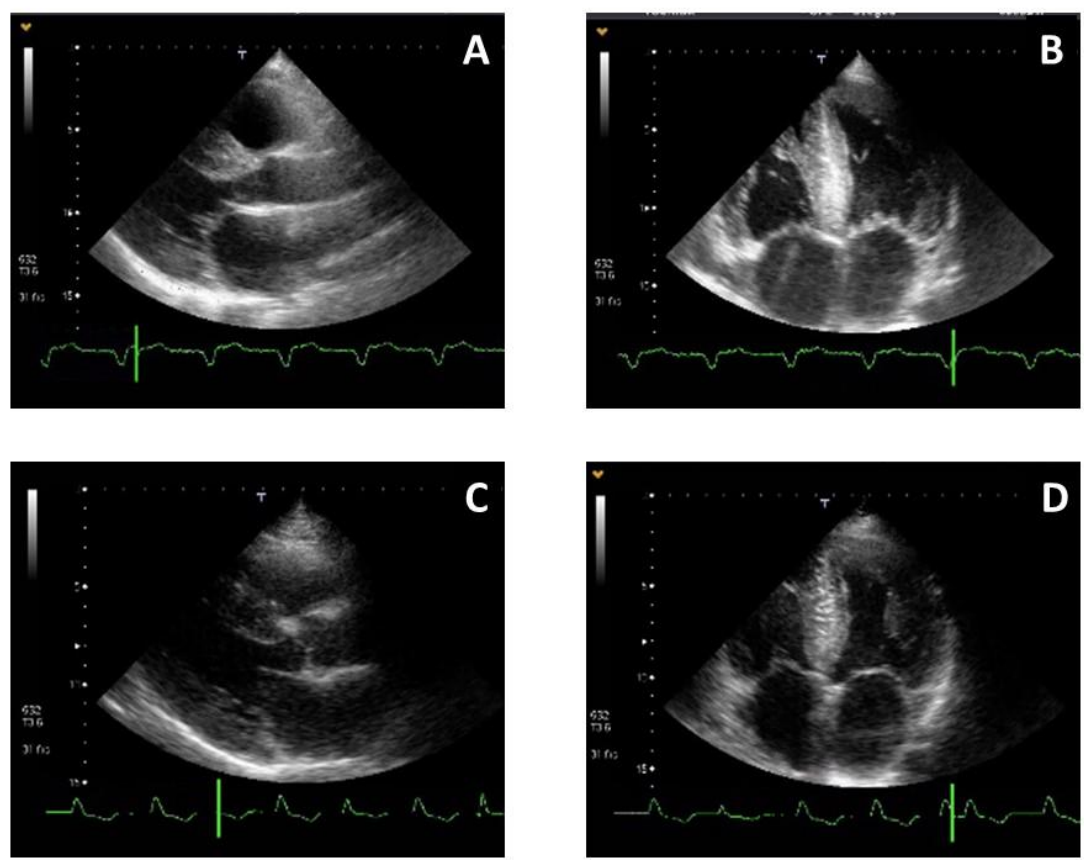

Figure 4. Transthoracic echocardiographic images of the patients with transthyretin amyloidosis.

Parasternal long axis (Panel A: Patient A; Panel C: Patient B) and apical four-chamber views (Panel B: Patient A; Panel D: Patient B). Morphological appearance of hypertrophic cardiomyopathy with diffuse left ventricular hypertrophy, enlarged atria, papillary muscle and right ventricular hypertrophy.

Coronarography did not confirm significant coronary disease. Hemodynamic examination showed increased end-diastolic left ventricular pressure (18-22 mmHg). Cardiac MRI showed preserved LV ejection fraction, concentric left ventricular hypertrophy, increased LV muscle mass and concentric, diffuse late contrast medium enhancement, suggesting amyloidosis. Assessment of a Jamshidi biopsy was negative towards multiple myeloma. Neurological electrophysiological assessment indicated predominant lower limb, axonal loss, motor polyneuropathy and bilateral carpal tunnel syndrome. DDD PM implantation was performed because of high degree AV block leading to syncope. Histological examination of myocardial biopsy showed accumulation of homogenic eosinophil, Congo red-positive material in the cardiac muscle, exhibiting green birefringence under polarised light, which was specific for amyloidosis (Figure 5, Panel A-C). Electron microscopy revealed dense, homogeneous material deposition in the cardiac muscle, which proved to be random set of resolved fibrils, without periodicity, on 35.000x magnification (average diameter of fibrils: $10.9 \mathrm{~mm}$ ). The ultrastructural study confirmed the light microscopic diagnosis of amyloidosis. Immunohistochemistry examination gave positive reaction with 
transthyretin antibody (Dako, polyclonal rabbit anti-human prealbumin, code A0002; antibody dilution 1:200; Figure 5, Panel D), but the serum amyloid A, the kappa and lambda light chain staining proved to be negative.
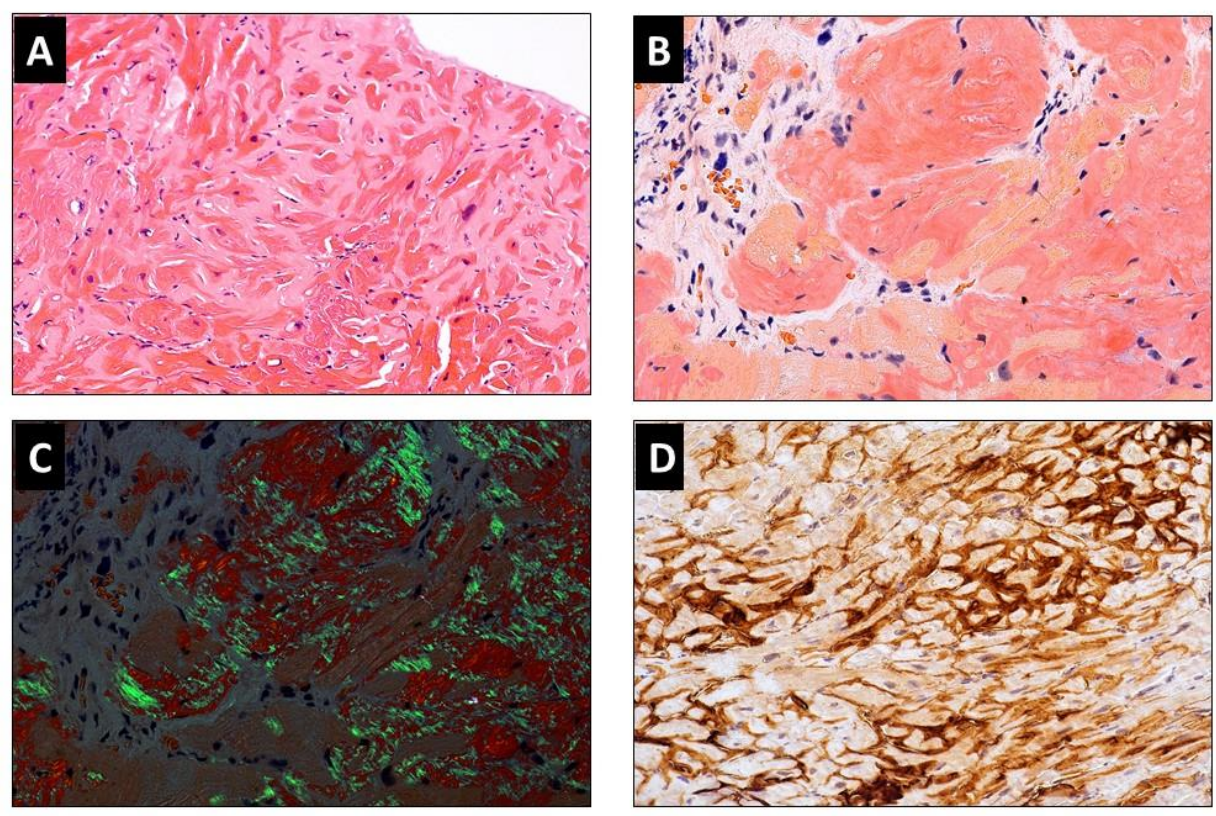

Figure 5. Histological assessment of myocardial biopsy samples. Accumulation of homogenic eosinophil material (Panel A), showing Congo red-positive staining (Panel B) and green birefringence under polarised light (Panel $C$ ) in the cardiac muscle, which is specific for amyloidosis. Immunohistochemistry examination gave positive reaction with transthyretin antibody (Panel D). Electron microscopy study confirmed the presence of amyloid fibrils (see case history).

\section{Patient B}

Past medical history of the 70 years-old male patient included tonsillectomy, GuillianBarre syndrome, L III-IV spinal surgery, hypertension, inguinal herniotomy and right wrist surgery because of carpal tunnel syndrome. Cardiovascular assessment was initiated because of exercise intolerance. ECG showed I degree AV block and left bundle branch block. Echocardiography indicated enlarged atria, normal left ventricle, decreased global left (LVEF 31\%) and right ventricular function. The morphological appearance of left ventricle was hypertrophic cardiomyopathy with hypertrophy in all of the left ventricular segments and also of the right ventricle. The maximum left ventricular wall thickness was $20 \mathrm{~mm}$ (Figure 4, Panel $C$ and D), without outflow tract obstruction, but increased pulmonary pressure $(60 \mathrm{mmHg})$ and marked diastolic dysfunction (E/Ea: 15). Cardiac MRI confirmed the echocardiographic results, the appearance of late contrast enhancement was 
specific for amyloidosis. NT-pro-BNP level was high (1977 pg/ml). During follow-up successful electrical cardioversion was performed because of multiple episodes of persistent atrial fibrillation. No significant coronary artery stenosis was seen on coronarography. Histological examination of myocardial biopsy showed extensive accumulation of homogenic eosinophil, Congo red-positive material in cardiac muscle, which exhibited green birefringence under polarised light, which was specific for amyloidosis. Electron microscopy study confirmed the light microscopic diagnosis of amyloidosis (average diameter of fibrils: $11 \mathrm{~nm}$ ). Immunohistochemistry examination gave intensive positive reaction with the Congo red-positive material, but the kappa and lambda light chain staining gave background staining, which was caused by a non-specific infiltration. 


\subsection{Methods}

\subsubsection{Molecular genetic analysis of $L A M P 2, G L A$ and $T T R$ genes}

The family members and patient's care-givers gave informed consent to molecular genetic investigations. Genomic DNA was isolated from peripheral blood samples according to standard methods (GeneJET Whole Blood Genomic DNA Purification Kit, Thermo Scientific). All the coding exons and flanking intronic regions of the LAMP2 (9 exons), GLA (7 exons) and TTR (4 exons) genes, comprising the whole coding sequence, were amplified by polymerase chain reaction with primers published in the literature. PCR products were directly cycle sequenced using BigDye Terminator v3.1 Cycle Sequencing Kit (Applied Biosystems) on an ABI Prism 310 Genetic Analyzer (Applied Biosystems). Electropherograms were analysed by Sequencing Analyzer v5.4 Software provided by the supplier.

\subsubsection{Restriction fragment analysis of the $L A M P 2$ mutations}

As both of the identified $L A M P 2$ mutations affected restriction sites for a commercially available restriction enzyme; both mutations were also analysed by restriction fragment analysis. In Family A, the mutation abolished the restriction site of the enzyme AlwNI, while in Family B, the mutation created an extra restriction site for enzyme BslI. Restriction analysis was done according to manufacturers' recommendations.

\subsubsection{Bioinformatics}

Nucleotide changes are reported according to the database of the European Molecular Biology Laboratory- European Bioinformatics Institute (Ensembl database, www.ensemble.org) using LAMP2-001 (ENST00000200639), GLA-001 (ENST00000218516), and TTR-001 (ENST00000237014.7) as a reference sequence. The annotation of the TTR variants was performed by the new nomenclature (taking into account the length of signal peptide, which consists of 20 amino acids).

\subsubsection{Linkage analysis}

The size of the family and the presence of affected family members in all three generations carrying the GLA p.Ile239Met mutation allowed us to conduct linkage analysis. Linkage analysis was done with the FASTLINK program. Linkage between the affection status and the mutation was modelled with the following parameters: disease allele frequency: 1:10.000, disease penetrance: $90 \%$. 


\section{RESULTS}

\subsection{Identification of $L A M P 2$ mutations in patients with Danon disease}

\subsubsection{Mutation data}

Two new mutations in the $L A M P 2$ gene were identified in the two index cases. In the index patient of Family A, a G-A transition was detected (c.962G>A) in exon 8 of the gene (Figure 6, Panel A), which changes the tryptophan coding TGG codon to a stop codon TAG, at codon 321 (p.Trp321Stop, nonsense mutation). In the proband of Family B, a 1 bp insertion in exon 8 (c.973insC) was found (Figure 6, Panel B), leading to a frame-shift mutation. Prediction analysis indicates the inclusion of 24 extra amino acids and a premature stop codon after the last normal amino acid proline at codon 324 (p.Pro324fs+24X). Corresponding base changes were present in the same position in the reverse strand. The two mutations were not present in 200 chromosomes of normal control subjects coming from the same geographical region.
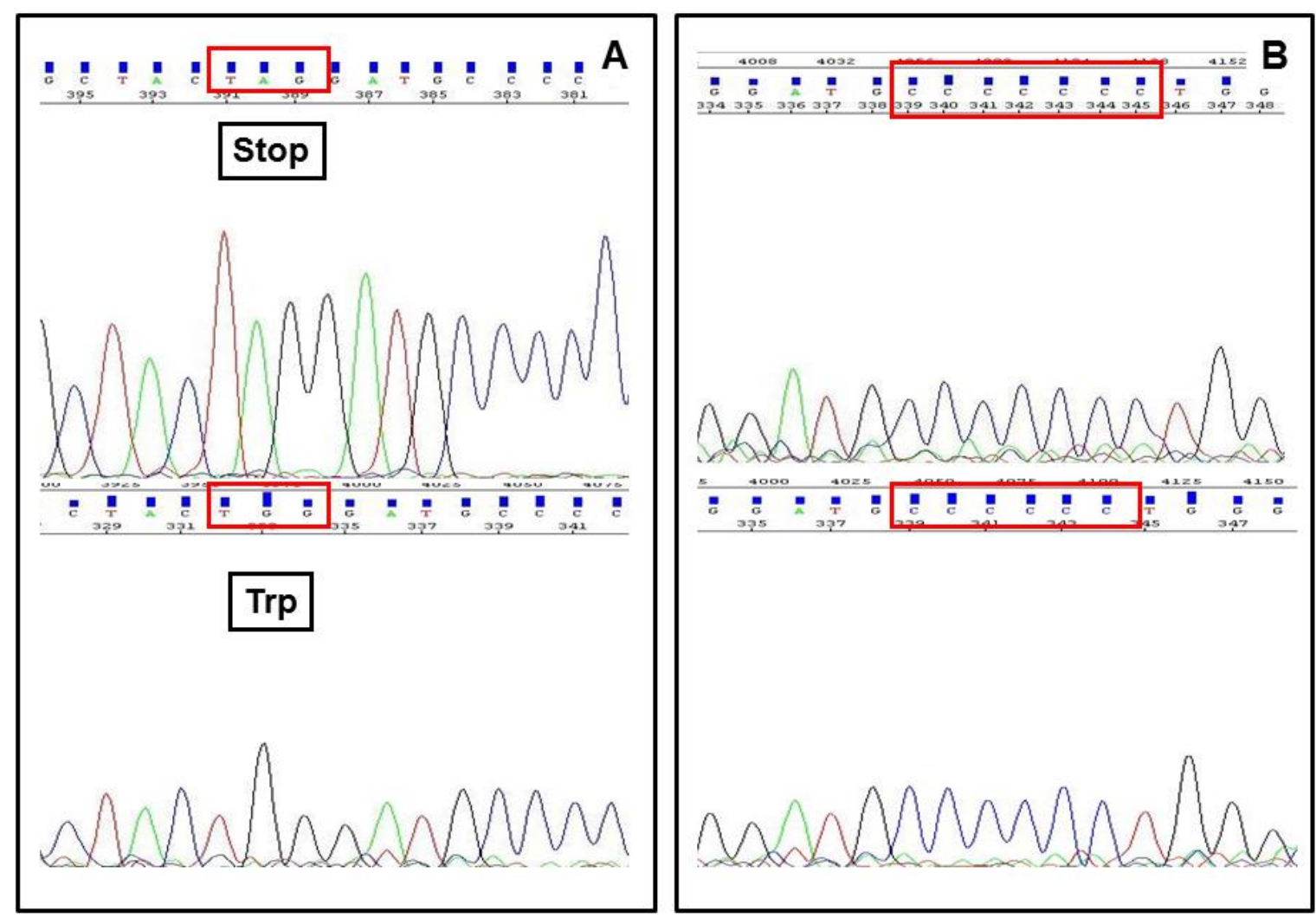

Figure 6. Sequence analysis of exon 8 of the LAMP2 gene. Panel A: In the index patient of Family A, sequencing shows a $G$-A transition in position 962 (c.962G>A) representing a stop codon TAG (upper sequence) as compared to the tryptophan coding normal TGG codon (lower sequence). Panel B: In the index patient of Family B, a 1 bp insertion in position 973 (c.973insC) is revealed (upper sequence) as compared to the normal sequence (lower sequence). 


\subsubsection{Restriction fragment analysis of the two LAMP2 gene mutations}

Both mutations altered restriction sites for a commercially available restriction enzyme; therefore, the two mutations were confirmed by restriction analysis. In Family A, the mutation abolished the restriction site (5'-CAGNNNCTG-3') of the enzyme AlwNI, while in Family B, the mutation created an extra restriction site (5'-CCNNNNNNNGG-3') for enzyme BslI. Restriction analysis pattern of amplified PCR products of mutation carriers were in full agreement with predicted effects of restriction site loss and gain, respectively (data are not shown).

\subsubsection{Bioinformatics}

Both mutations were predicted to lead to a truncated LAMP-2 protein with a complete loss of the transmembrane domain and the short cytoplasmic tail of the protein. This part of the protein is well conserved among different species and among human splice variants of the $L A M P 2$ gene and is presumed to be deleterious.

\subsubsection{Genetic screening of Family $A$ and Family $B$}

In Family A, DNA was available from the grandmother (subject I:2 in Family A), mother (subject II:1 in Family A), two sisters (subject III:2 and subject III:4 in Family A) and a cousin (subject III:5 in Family A). They all proved to be carriers of the mutation (Figure 1). In Family B, DNA was available from the mother (subject I:1 in Family B) and the brother subject II:2 in Family B). The proband's mother carried the mutation, while the brother did not (Figure 1).

\subsubsection{Clinical course of LAMP2 gene mutation carrier family members}

Altogether, 11 family members were screened in the two families, while genetic analysis was possible in 9 family members. Eight family members proved to be carriers of either $L A M P 2$ gene mutations. Out of the eight mutation carrier family members, four proved to be clinically not affected (in terms of development of cardiomyopathy at last follow up). In addition to the four penetrant cases with DNA diagnosis we identified two additional family members with a suggestive manifestation of Danon disease (subjects II:3 and II:6 in Family A). This made up 6 patients in the two families with proven or likely diagnosis of the disease (Table 3).

Average age at the onset of the disease was $21 \pm 12$ years, which was clearly lower in males than in females $(16 \pm 5$ vs. $31 \pm 18$ years, no statistical comparison was made due to small 
Table 3. Demographic and clinical characteristics of clinically or genetically affected family members of Family A and Family B

\begin{tabular}{|c|c|c|c|c|c|c|c|c|c|c|}
\hline Family & Subject & Sex & $\begin{array}{c}\text { Age (years, at } \\
\text { diagnosis/last FU or } \\
\text { death) }\end{array}$ & $\begin{array}{c}\text { Length } \\
\text { of FU } \\
\text { (years) }\end{array}$ & $\begin{array}{l}\text { Died of } \\
\text { disease }\end{array}$ & $\begin{array}{l}\text { Clinically } \\
\text { affected }\end{array}$ & $\begin{array}{l}\text { Genetically } \\
\text { affected }\end{array}$ & $\begin{array}{c}\text { Cardiac } \\
\text { phenotype }\end{array}$ & $\underset{(\mathbf{m m})}{\operatorname{LVmax}}$ & Clinical course \\
\hline A & $\mathrm{I}: 2$ & female & $44 / 60$ & 16 & yes & yes & yes & $\mathrm{HCM}$ & 15.4 & $\mathrm{AF}, \mathrm{PM}$ implantation, died of heart failure \\
\hline A & II: 1 & female & $\mathrm{NA} / 44$ & NA & no & no & yes & normal & 12 & negative $\mathrm{T}$ waves in $\mathrm{V} 4-\mathrm{V} 6$ \\
\hline A & II: 3 & male & $23 / 34$ & 11 & yes & yes & ND & $\mathrm{HCM}$ & 25 & $\mathrm{AF}, \mathrm{AVB}, \mathrm{PM}$ implantation, died at age 34 \\
\hline A & II:6 & female & $18 / 24$ & 6 & yes & yes & ND & $\mathrm{HCM}$ & 18 & $\mathrm{AF}$, progression into dilated phase, died of SCD \\
\hline A & III:1 & male & $12 / 23$ & 11 & no & yes & yes & $\mathrm{HCM}$ & 39 & $\begin{array}{c}\text { limb-girdle muscle dystrophy, mental retardation, } \\
\text { AF, ICD implantation, progression into dilated } \\
\text { phase }\end{array}$ \\
\hline A & III:2 & female & $\mathrm{NA} / 25$ & NA & no & no & yes & normal & 10.7 & \\
\hline A & III:4 & female & $\mathrm{NA} / 21$ & NA & no & no & yes & normal & 11.2 & \\
\hline A & III:5 & male & $13 / 17$ & 4 & no & yes & yes & $\mathrm{HCM}$ & 42 & $\begin{array}{l}\text { WPW, limb-girdle muscle dystrophy, mental } \\
\text { retardation, progression into dilated phase }\end{array}$ \\
\hline $\mathrm{A}$ & III:6 & male & $20 / 29$ & 9 & yes & yes & ND & $\mathrm{HCM}$ & 23 & $\begin{array}{l}\text { muscle dystrophy, AF, ICD implantation, } \\
\text { progression into dilated phase, died of HF at age } \\
29\end{array}$ \\
\hline B & $\mathrm{I}: 1$ & female & $\mathrm{NA} / 48$ & NA & no & no & yes & normal & 10 & $\mathrm{RF}$ ablation because of atrial flutter \\
\hline B & II: 1 & male & $14 / 20$ & 6 & yes & yes & yes & $\mathrm{HCM}$ & 28 & $\begin{array}{l}\text { CK rise, PSVT, accessory pathway, ICD } \\
\text { implantation, died of intractable heart failure }\end{array}$ \\
\hline
\end{tabular}

FU: follow-up; LVmax: maximal left ventricular wall thickness; NA: not applicable; ND: not done; HCM: hypertrophic cardiomyopathy; AF: atrial fibrillation; AVB: highdegree AV block, PM: pace maker; SCD: sudden cardiac death; ICD: implantable cardioverter defibrillator; RF: radio-frequency; CK: creatine kinase; PSVT: paroxysmal supraventricular tachycardia 
sample sizes). The cardiac manifestation was hypertrophic cardiomyopathy in all cases, including female patients. Atrial fibrillation was observed in 4 cases, and atrial flutter in one non-penetrant case. Sustained or non-sustained supraventricular tachycardia was noted in almost all cases. Pace-maker implantation was necessary in two cases, due to high degree AV block. An ICD was implanted in two cases, one for primary, one for secondary prevention.

Out of the 6 clinically manifest patients, four patients (67\%) died at an average age of $35 \pm 18$ years. The age of death was clearly lower in males than in females ( $27 \pm 10$ vs. $42 \pm 25$ years). The average time span from the time of diagnosis to death was $10 \pm 5$ years. The mode of death was heart failure in three cases and sudden cardiac death in one case. An additional aborted sudden cardiac death occurred in another case.

\subsection{Identification of $G L A$ mutations in patients with Fabry disease}

We identified 4 GLA mutations in 4 patients $(4 / 21,19 \%)$ out of 21 patients we screened (4 women, average age $49 \pm 15$ years) [p.Ile239Met (c.717A>G); p.Tyr397Stop (c.1191T>G), c.548-57_-56dupTA; p.Glu358Lys (c.1072G>A)]. Three mutations out of the 4 identified mutations were found in patients with the phenotype of left ventricular hypertrophy or hypertrophic cardiomyopathy comprising 18 cases, therefore the prevalence of GLA mutation in this sub-group was $17 \%$ (3/18). The fourth mutation (p.Glu358Lys) caused ocular symptoms (cornea verticillata), which indicated the screening, but without substantial cardiac alterations in a female patient.

\subsection{1. p.Ile239Met mutation}

We detected a previously unreported heterozygous mutation in exon 5 of the GLA gene in the index patient (c.717A $>$ G; Figure 7). The mutation changes the ATA triplet at codon 239, encoding for isoleucine, to ATG, encoding for methionine (p.Ile239Met, missense mutation). This mutation is located in a weakly conserved nucleotide and moderately conserved amino acid position, with small physicochemical differences between the amino acids isoleucine and methionine. Software analyses by PolyPhen-2, SIFT and Mutation Taster indicate that this mutation is probably damaging. Corresponding base changes were present in the same position in the reverse strand. To date, this mutation is not described in 


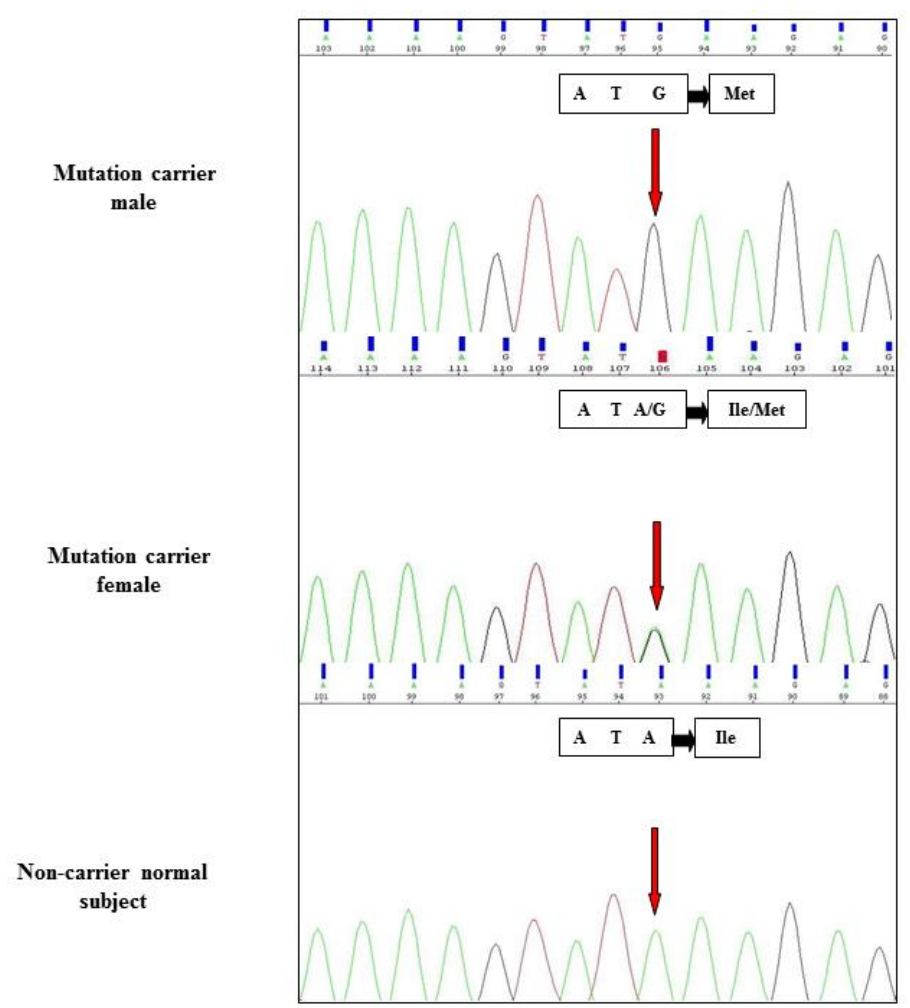

Figure 7. Sequence analysis of exon 5 of the GLA gene illustrating a c.717A>G nucleotide transition. The mutation changes the ATA triplet at codon 239, encoding for isoleucine, to ATG, encoding for methionine (p.Ile239Met). The sequence of a mutation carrier, hemizygous male; of a mutation carrier heterozygous female, and of a non-carrier normal subject is shown.

the Exome Aggregation Consortium, Exome Sequencing Project or the 1000 Genomes Browser.

Past medical history of the p.Ile239Met mutation carrier Hungarian female index patient (subject H 332.0, see family tree in Figure 8 and Table 4) included nephrology assessment at age of 43 years because of proteinuria which was interpreted as to be due to mesangioproliferative glomerulonephritis. Angina pectoris, ischemic heart disease and left ventricular hypertrophy, diagnosed at age of 63 years, were also known. That time, renal insufficiency worsened and necessitated continuous ambulatory peritoneal dialysis, and later hemodialysis. At age of 67 years she received a successful renal transplant but rejection occurred 2 years later, and hemodialysis continued. At age of 69 years the patient came to cardiology attention because of syncopal episodes which proved to be caused by intermittent $2^{\text {nd }}$ degree, 2:1 atrio-ventricular (AV) block. Echocardiography revealed marked LV hypertrophy in the form of obstructive hypertrophic cardiomyopathy with a left ventricular outflow tract gradient of $120 \mathrm{mmHg}$ measured at a heart rate of $40 / \mathrm{min}$ due to the 2:1 AV block. The morphology of the heart was hypertrophic cardiomyopathy with marked left ventricular hypertrophy (maximal LV wall thickness $27 \mathrm{~mm}$ ), papillary 


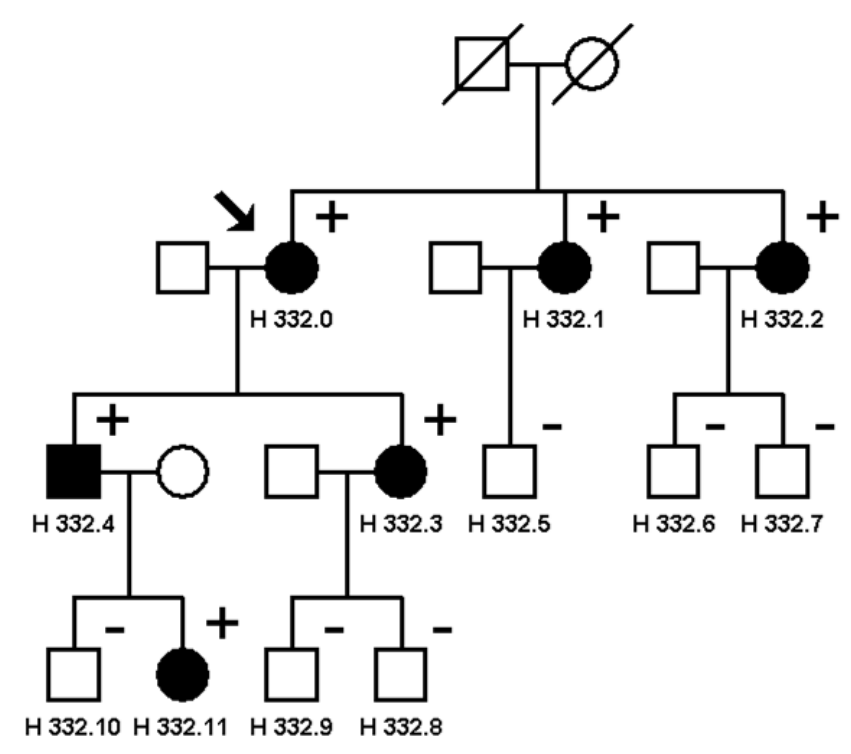

Figure 8. Pedigree of the p.Ile239Met GLA gene mutation carrier family. Squares and circles denote males and females, respectively; filled symbols indicate clinically affected family members. Arrow point to the index patient. Deceased individuals are slashed. Mutation carriers are labelled with a plus (+) sign, and non-carriers with a minus (-) sign.

muscle hypertrophy and right ventricular (RV) hypertrophy (maximal RV wall thickness $14 \mathrm{~mm}$ ) (Figure 9). NT-pro-BNP levels were extremely high (>35.000 pg/ml, upper limit of normal: $<200 \mathrm{pg} / \mathrm{ml}$ ). Because of the high degree AV block a dual-chamber pace-maker implantation was performed, and the outflow tract gradient decreased to $20 \mathrm{mmHg}$ with the optimisation of the AV delay.

Further examinations revealed neither angiokeratomas nor cornea verticillata on dermatological and ophthalmological assessments. Ear, nose and throat examination revealed perception hypoacusis. Neurological assessment indicated a left side dominant paraparesis which was more prominent distally, with a muscle strength of 3-4/5. Electromyography and electroneurography indicated primarily motor neuropathy with axonal loss, without myopathy. Current laboratory findings include elevated renal function (UN: $16.1 \mathrm{mmol} / \mathrm{L}$; creatinine: $294 \mu \mathrm{mol} / \mathrm{L}$; eGFR: $13.7 \mathrm{~mL} / \mathrm{min} / \mathrm{m}^{2}$ ) and lyso-Gb3 level (10,6 ng/ml, upper limit of normal+2SD: $<1.8 \mathrm{ng} / \mathrm{ml})$.

\section{Family members}

The index patient belongs to a three-generation family (see family tree in Figure 8). Altogether, twelve family members ( 5 females, 7 males, average age: $45 \pm 17$ years, see family tree in Figure 8 and Table 4) were available for clinical and genetic screening.

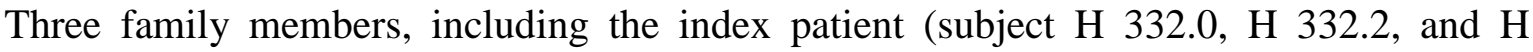
332.4), manifested the cardiac phenotype of hypertrophic cardiomyopathy (defined as 
Table 4. Demographic and clinical characteristics of genetically affected family members carrying the GLA p.Ile239Met mutation

\begin{tabular}{|c|c|c|c|c|c|c|c|c|c|}
\hline Subject & Sex & $\begin{array}{c}\text { Age } \\
\text { (years) }\end{array}$ & $\begin{array}{c}\text { Cardiac } \\
\text { morphology }\end{array}$ & ECG changes & $\underset{(\mathbf{m m})}{\operatorname{LVmax}}$ & $\begin{array}{l}\text { LV mass } \\
(\mathrm{g})\end{array}$ & $\begin{array}{l}\text { GLA enzyme } \\
\text { level }(\mu \mathrm{mol} / \mathrm{l} / \mathbf{h})^{*}\end{array}$ & $\begin{array}{c}\text { lyso-Gb3 } \\
\text { level }(\mathrm{ng} / \mathrm{ml})\end{array}$ & $\begin{array}{l}\text { Other organ } \\
\text { involvement }\end{array}$ \\
\hline Н 332.0 & female & 69 & $\mathrm{HCM}$ & $\begin{array}{l}\text { 2nd degree AV block, LVH, } \\
\text { intraventricular conduction delay }\end{array}$ & 27 & ND & ND & 10.6 & renal failure \\
\hline Н 332.1 & female & 73 & $\mathrm{LVH}$ & $\begin{array}{c}\text { negative } \mathrm{T} \text { waves in leads I-aVL, } \\
\text { V2-6 }\end{array}$ & 13 & 107 & ND & 2.4 & $\begin{array}{c}\text { non-significant } \\
\text { proteinuria }\end{array}$ \\
\hline Н 332.2 & female & 62 & $\mathrm{HCM}$ & $\begin{array}{c}\text { LVH, negative T waves in leads } \\
\text { I-aVL, V4-6 }\end{array}$ & 16 & 131 & ND & 4.2 & $\begin{array}{c}\text { non-significant } \\
\text { proteinuria }\end{array}$ \\
\hline Н 332.3 & female & 52 & $\mathrm{LVH}$ & $\begin{array}{l}\text { negative } \mathrm{T} \text { waves in leads II-III- } \\
\text { aVF, V4-6 }\end{array}$ & 14 & 144 & ND & 2.9 & - \\
\hline Н 332.4 & male & 49 & $\mathrm{HCM}$ & $\begin{array}{l}\text { LVH, negative T waves in leads } \\
\text { II-III-aVF, V4-6 }\end{array}$ & 20 & 268 & $<0.2$ & 13.8 & - \\
\hline H 332.11 & female & 26 & none & none & 8 & 87 & ND & 3.2 & - \\
\hline
\end{tabular}

ECG: electrocardiogram; LVmax: maximal left ventricular wall thickness; GLA: $\alpha$-galactosidase A; lyso-Gb3: lysosomal globotriaosyl-ceramide;

ND: not done; HCM: hypertrophic cardiomyopathy; LVH: left ventricular hypertrophy

*upper limit of normal $\pm 2 S D: \geq 2.6 \mu \mathrm{mol} / \mathrm{l} / \mathrm{h}$

** upper limit of normal $+2 S D: \leq 1.8 \mathrm{ng} / \mathrm{ml}$ 
maximal LV wall thickness $\geq 15 \mathrm{~mm}$ ). The degree and distribution of cardiac hypertrophy was highly variable: while it was most marked at the interventricular septum in the index patient, it affected mostly the inferior septum and the infero-postero-lateral wall of the left ventricle in the son of the index patient (Figure 9). Two other family members (subject $\mathrm{H}$ 332.1 and $\mathrm{H}$ 332.3) were diagnosed with LV hypertrophy (defined as maximal LV wall thickness $\geq 12 \mathrm{~mm}$ ). ECG changes indicating LV hypertrophy and repolarisation changes were present in all patients with echocardiographic evidence of LV hypertrophy. A further family member, the 26-years-old niece of the index patient (subject $\mathrm{H} 332.11$ ) did not exhibit cardiac phenotype, but showed increased lyso-Gb3 levels. Non-significant proteinuria was present in two family members. No other family member showed other extra-cardiac (renal, central and peripheral nervous system, skin, eye, etc.) manifestation of the disease.

All the available twelve family members were genotyped for the GLA p.Ile239Met mutation. Six family members carried the mutation ( 5 females, 1 male, average age: $55 \pm 16$ years, see family tree in Figure 8 and Table 4). Taken affection status as the presence of hypertrophic cardiomyopathy, LV hypertrophy or elevated lyso-Gb3 levels, all affected family members carried the mutation while all non-affected family members were noncarriers. Linkage analysis of the family gave a two-point LOD score of 2.01 between the affection status and the presence of the p.Ile239Met GLA mutation, strongly supporting linkage. Lyso-Gb3 levels were elevated in all carrier family members (range: 2.4-13.8 $\mathrm{ng} / \mathrm{ml}$; upper limit of normal+2 STD: $\leq 1.8 \mathrm{ng} / \mathrm{ml}$ ). The GLA enzyme level was markedly reduced in the affected male family member $(<0.2 \mu \mathrm{mol} / \mathrm{l} / \mathrm{h}$; upper limit of normal \pm 2 STD): $\geq 2.6 \mu \mathrm{mol} / \mathrm{l} / \mathrm{h})$.

\subsection{2. p.Tyr397Stop mutation}

The second mutation, a T-G transition in exon 7 of the $G L A$ gene (c.1191T $>\mathrm{G}$ ), which changes the tyrosine to a stop codon, at codon 397 (p.Tyr397Stop, nonsense mutation) was identified in a female patient (Figure 10).

Past medical history of the 47 years-old female patient included known and treated hypercholesterinaemia. The patient was admitted to the hospital due to the symptoms comprising visual disturbance, tremor, numbness in arms and legs, and speech disorder. Symptoms ceased spontaneously within an hour, and the diagnosis of transient ischemic attack due to circulatory disturbance in the region of right medial cerebral artery was suggested on acute neurological and CT examination. 

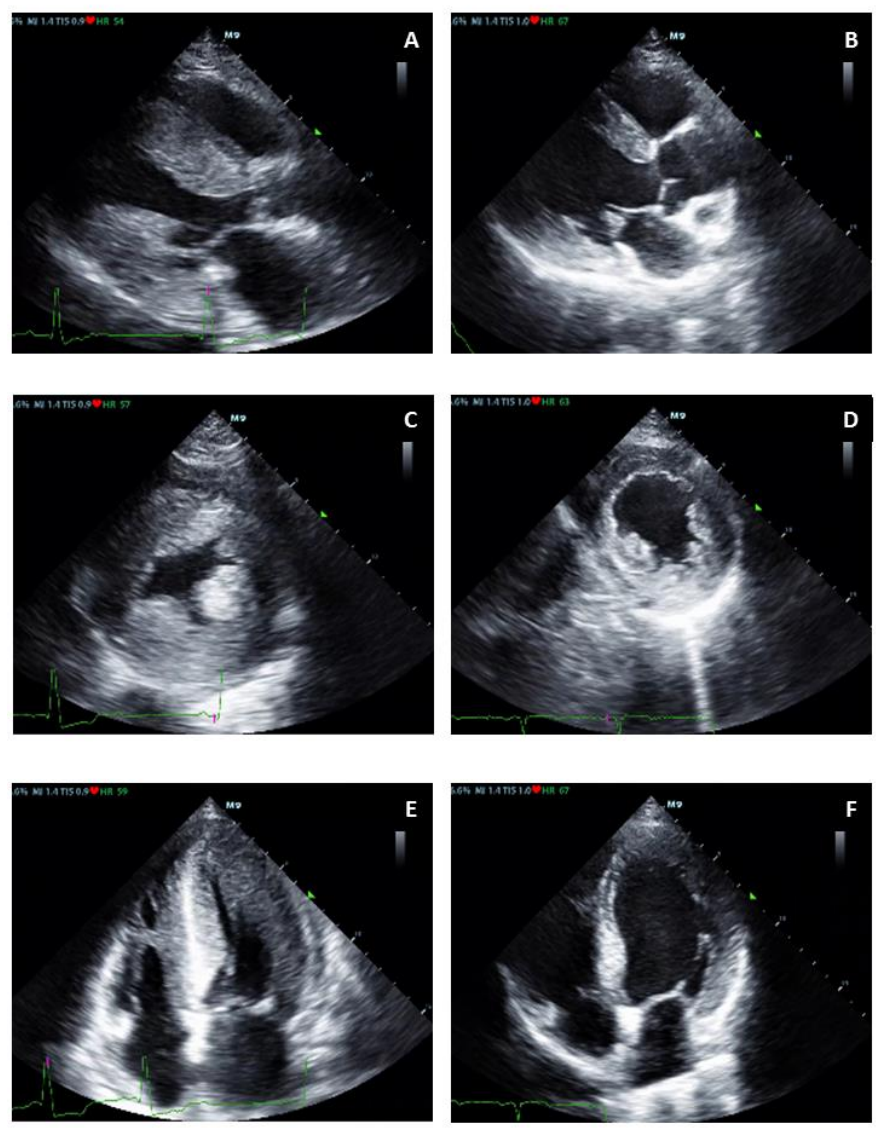

Figure 9. Transthoracic echocardiography images of hypertrophic cardiomyopathy in the index patient (subject H 332.1) and her son (subject H 332.4) illustrating heterogeneity in the extent and distribution of left ventricular hypertrophy. In the index patient marked left ventricular hypertrophy (maximal LV wall thickness $27 \mathrm{~mm}$ ) is seen, predominating at the interventricular septum, with papillary muscle hypertrophy and right ventricular hypertrophy (Panels $A, C$ and $E$ ). In the affected son the hypertrophy affects mostly the inferior septum and the infero-postero-lateral wall of the left ventricle (Panels $B, D$ and $F$ ). Parasternal long axis view (Panels $A$ and B), parasternal short axis view (Panels $C$ and D), and apical four-chamber view (Panels $E$ and $F$ ) of transthoracic echocardiography.

Doppler examination of carotid arteries did not show any abnormalities. ECG showed sinus rhythm, normal axis, left ventricular hypertrophy with signs of strain, negative Twaves in leads V3-6 (Figure 11). Echocardiography indicated concentric left ventricular hypertrophy (septum: $15 \mathrm{~mm}$, posterior wall thickness: $13 \mathrm{~mm}$ ) with preserved global left ventricular function and signs of marked diastolic dysfunction (increased E/E' ratio: >15, enlarged left atrium). During cardiac MRI late contrast enhancement in the ventricular muscle was not seen. Laboratory findings showed normal renal function, but proteinuria was confirmed. Further examinations revealed cornea verticillata on both sides during ophthalmology assessment, but angiokeratomas were not confirmed during dermatology examination. Cranial MRI described multiple white matter lesions and varicose veins. Ear, nose and throat examination did not reveal any spontaneous vestibular symptoms. The lyso-Gb3 level of the patient was elevated $(9,41 \mathrm{ng} / \mathrm{ml}$, reference $<1,6 \mathrm{ng} / \mathrm{ml})$. In addition 
to the conservative treatment including $\mathrm{ACE}$ inhibitor and beta-blocker, enzyme replacement therapy started (agalsidase alfa), and the clinical status of the patient is stable. During family screening two additional family members (the son and daughter of the proband) proved to be affected.

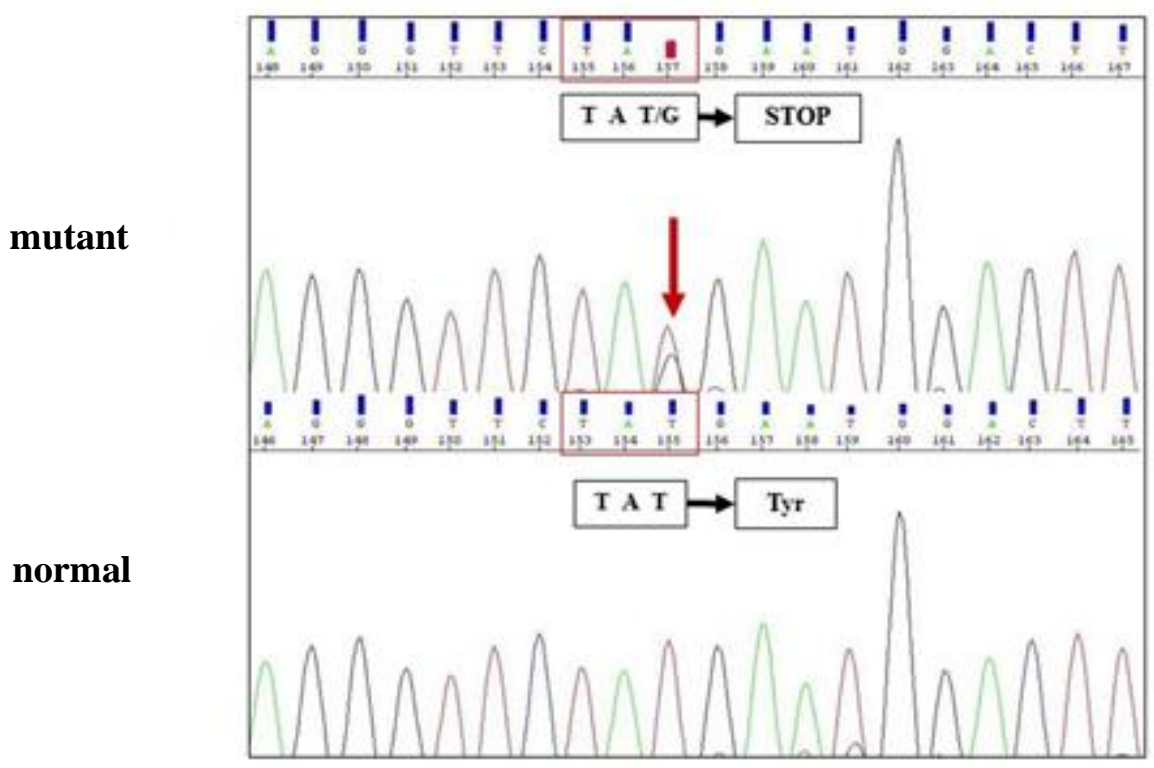

Figure 10. Sequence analysis of GLA gene exon 7 in mutant and normal samples. In the position 1191 of the cDNA, a T-G transition was detected (c.1191T>G) in exon 7 of the gene, which changes the tyrosine codon to Stop codon, at codon 397 (p.Tyr397Stop, missense mutation).

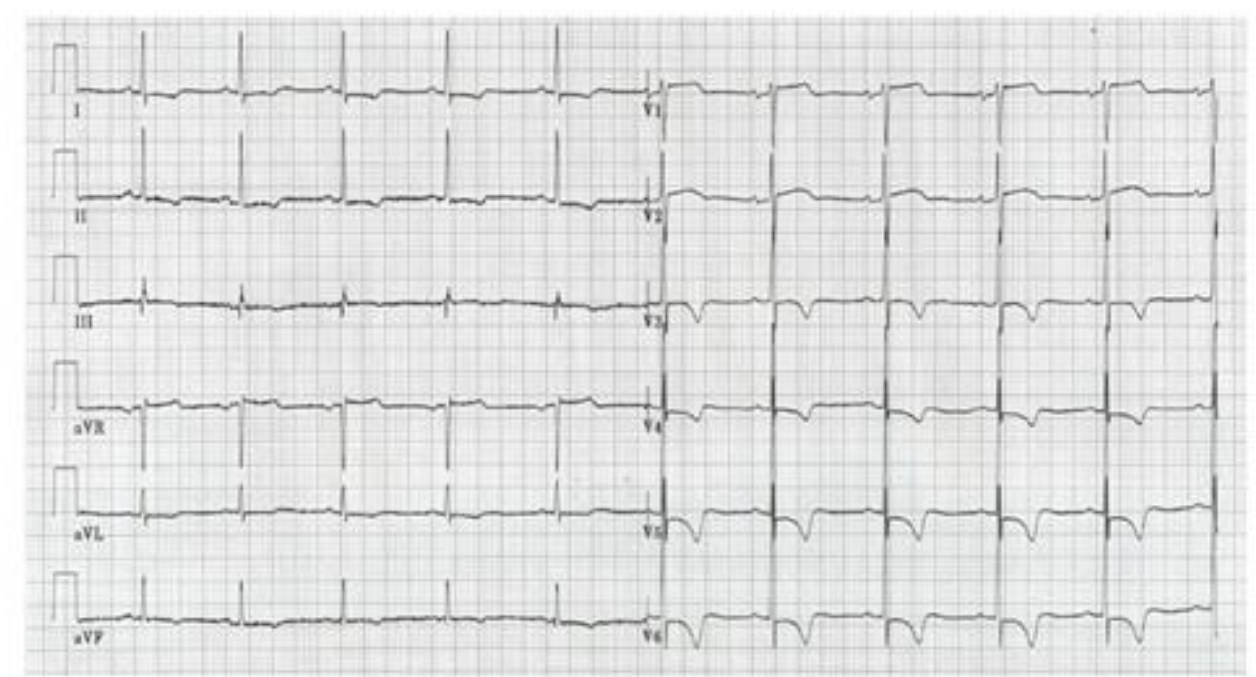

Figure 11. 12-lead resting ECG of the p.Tyr397Stop GLA mutation carrier Fabry patient. 60/min sinus rhythm, normal axis, left ventricular hypertrophy with signs of strain, negative T-waves in leads V3-6. Paper speed $25 \mathrm{~mm} / \mathrm{s}$, calibration $1 \mathrm{~mm} / \mathrm{mV}$. 


\subsection{3. c.548-57_-56dupTA mutation}

The third variant, a two base-pair duplication in intron 3 of the gene (c.548-57_-56dupTA) was identified in a 40-year-old female patient with an atypical, rapidly-progressing, restrictive cardiomyopathy. Past medical history of the patient included treatment for systemic lupus erythematosus (SLE). Cardiac assessment was initiated because of elevated necroenzyme levels, but initially echocardiography revealed preserved systolic function with signs of mild diastolic dysfunction. Recurrent loss of consciousness due to IIIrd degree AV block necessitated pacemaker implantation. Despite medical therapy heart failure symptoms progressed quickly, and the patient progressed from NYHA I to NYHA III functional status in six months. Echocardiography that time showed severely impaired diastolic function with very high $7982 \mathrm{pg} / \mathrm{ml}$ NTproBNP values. Myocardial biopsy was performed, which revealed Fabry-like cardiomyopathy. Despite conservative therapy, rapid progression of the condition was observed, and the patient was referred for heart transplantation. After temporary ventricular assist device therapy, the patient received a successful heart transplant, but soon after the patient died because of rejection.

\subsection{4. p.Glu358Lys mutation}

The fourth GLA mutation, a G-A transition in exon 7 (c.1072G>A), which changes the acidic glutamate to basic lysine, at codon 358 (p.Glu358Lys, missense mutation) was identified in a female patient with cornea verticillata.

Past medical history of the 28-years-old female patient included tonsillectomy because of tinnitus and chronic tonsillitis. Cornea verticillata was detected during ophthalmological examination, due to accidental foreign body in the eyes. Laboratory findings showed abnormally low alpha galactosidase enzyme activity value $(3,7 \mathrm{nmol} / \mathrm{mg} / \mathrm{h}$, upper limit of normal: $>15,6 \mathrm{nmol} / \mathrm{mg} / \mathrm{h})$. ECG revealed sinus rhythm, normal PQ and QT interval, narrow QRS width with flat, negative T-waves in lead III. Echocardiography showed normal-sized heart chambers, preserved global left ventricular function, without segmental wall motion abnormality. The maximum left ventricular wall thickness was $9 \mathrm{~mm}$. Cardiac MRI did not prove hypertrophic cardiomyopathy or late contrast enhancement. Neither neurological nor nephrological examination revealed any abnormalities, suggesting Fabry disease. 


\subsection{Identification of $T T R$ mutations in patients with transthyretin amyloidosis}

Two non-synonymous TTR gene variants were identified in the two patients with transthyretin amyloidosis.

In Patient $A$, an $A-G$ transition was detected $(c .323 A>G)$ in exon 3 of the gene, which changes the histidine coding CAT codon to an arginine coding CGT codon, at codon 108 (p.His108Arg, missense mutation, Figure 12). Among the first-generation relatives of the index patient, the genetic analysis of his mother's blood sample was possible, who died because of heart failure at age of 85 years. Her mutation carrier status was positive.

In Patient B, a G-A transition in exon 2 (c.76 G>A) was found, which changes the glycine coding GGT codon to a serine coding codon AGT (p.Gly26Ser). Corresponding base changes were present in the same position in the reverse strand. A synonymous polymorphism, not changing the amino acid sequence, was also detected in the second proband (c.57G>A, Glu19Glu).

normal

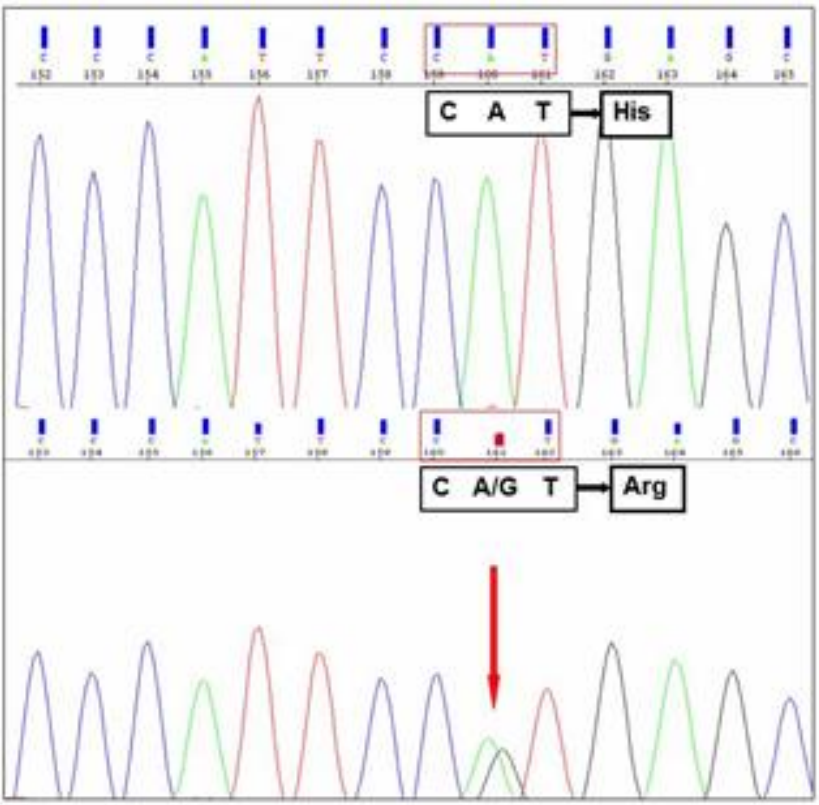

Figure 12. Sequence analysis of TTR gene exon 3 in mutant and normal samples. In the position 323 of the cDNA of Patient A, a A-G transition was detected $(c .323 A>G)$ in exon 3 of the gene, which changes the histidine coding CAT codon to an arginine codon CGT, at codon 108 (p.His108Arg, missense mutation). 


\section{DISCUSSION}

\subsection{Identification of $L A M P 2$ mutations in patients with Danon disease}

By screening two HCM patients with marked concentric hypertrophy and pre-excitation on the ECG we identified two novel LAMP2 gene mutations in two families with Danon disease. Both mutations were predicted to lead to a truncated LAMP-2 protein lacking the transmembrane and cytoplasmic domains. We observed a highly malignant phenotype in both families characterised by a large proportion of disease related death.

To the best of our knowledge, one of our families, Family A, is one of the largest family with Danon disease reported to date, in terms of number of affected family members with a proven DNA diagnosis. There are a small number of large families reported in the literature (31-34), beside numerous small families (10, 31, 32, 35). However, in the majority of large families a very significant number of the family members, supposed to be affected, were already deceased at the time of the report, with no material available for DNA investigation and therefore no chance to have a definite genetic diagnosis of the disease $(32,33)$. In these cases, although the affection status is suggestive, cannot be taken as proven, which leaves some uncertainty about the clinical phenotype described. In our two families, we identified altogether 8 gene mutation carriers (six in Family A and two in Family B) which clearly helped to draw conclusions about the clinical course of the disease in our families.

In both index cases, the clinical manifestation of the disease was typical for Danon disease, with extreme concentric LV hypertrophy, pre-excitation on the ECG, muscle dystrophy or CK rise, and variable mental retardation $(36,37)$. The cardiac phenotype in the affected family members, including female family members was hypertrophic cardiomyopathy, and a high prevalence of arrhythmias or bradyarrhythmias, necessitating PM implantations. Four disease related deaths occurred in the families, at an average age of $35 \pm 18$ years, which was clearly lower in males than in females ( $27 \pm 10$ vs. $42 \pm 25$ years).

Although RF ablation procedures have been used to treat arrhythmias in Danon disease, results of an electrophysiological study are surprisingly rarely reported in such patients. In one of our patients (subject II:1, Family B), an EP study was performed twice, with unusual findings. In one EP study, the accessory pathway was mapped to the anterior region of the left AV ring, which is a very unusual location of accessory pathways, present in $0-1 \%$ of patients with WPW syndrome. In addition to the induction of the AV tachycardia, non-sustained atrial arrhythmias were also inducible. Further to this, another 
genetically affected family member (subject I:1, Family B), without manifesting cardiomyopathy, also underwent an EP study because of multiple atrial tachycardias with macro-reentrant circuits and focal origin involving both atria. This observation raises the possibility of the presence of a disease substrate affecting the atria, and pointing to atrial arrhythmias as one of the early manifestations of the disease.

In our patient evaluated by cardiac biopsy, vacuolar cardiomyopathy was seen which displayed certain features that did not entirely fit to the published morphology of Danon disease. Although severely hypertrophied cardiac myocytes with extensive vacuolisation were seen in our case, the sarcoplasmic glycogen content was neither markedly increased, nor diastase-sensitive PAS-positive granules were encountered, thus the diagnosis of glycogen storage disease-induced cardiomyopathy was not proven on histological grounds. However, the ultrastructural analysis of the cardiomyocytes revealed increased number of lysosomal structures. Although normal hearts can display glycogen particles in lysosomes, the common presence of glycogen particles in the autophagic vacuoles and the frequent ruptures of these vacuoles indicated that the smoldering accumulation of diseased autolysosomes and subsequent chronic cellular injury could be a key process in the evolution of the vacuolar cardiomyopathy. Similar to the one of the patients with LAMP2 gene mutation described in the paper of Arad et al. (19), distinct PAS-positive inclusions corresponding electron microscopically to autolysosomes filled with relatively homogeneous dense material were seen in the myocytes of our patient. We performed diastase digestion and the globules proved diastase-resistant thus these inclusions seemed not be engaged with glycogen accumulation in lysosomes. Nevertheless, we regard them as manifestation of altered cellular digestion in the cardiomyocytes.

The characteristics of the two novel mutations, identified by us, are in agreement with literature data. The professional version of the Human Gene Mutation Database (HGMD, www.hgmd.org) lists 61 LAMP2 gene mutations causing Danon disease. About one quarter of the reported mutations are point mutations, the majority (about $80 \%$ ) of them being nonsense mutations, predicted to lead to a stop-codon. Another one-third of the mutations are small insertions or deletions, leading to frame-shift. An additional one-quarter of the mutations represent splice site mutations, with a variable and unpredictable expression. Gross deletions and insertions are also reported in the literature $(36,38,40,41)$. According to this, the overwhelming majority of the mutations reported to date, represent loss of function mutations which lead to a complete or almost complete loss of LAMP-2 protein expression. Almost all of the mutations are private mutations, although some mutations 
were reported to appear in multiple families. One of the mutation we identified, p.Trp321Stop, is a nonsense point mutation, presumably leading to premature stop codon at codon 321. The other mutation we described, p.Pro324fs $+24 \mathrm{X}$, is a one-base pair insertion which is predicted to lead a frame-shift and incorporation of 24 amino acids before activation of a hidden stop codon. Neither mutation has been described previously. Of note, the latter mutation has been found in the COSMIC database, in melanoma cells, perhaps delineating a higher mutation rate of this region.

\subsection{Identification of $G L A$ mutations in patients with Fabry disease}

Various strategies have been used to estimate the prevalence of Fabry disease in patients presenting left ventricular hypertrophy or HCM, each yielding different results (Table 5). The first major study by Nakao et al examined 1603 men undergoing routine echocardiography. The measurement of $\alpha$-galactosidase A activity in plasma samples revealed that seven (3\%) out of 230 patients with otherwise unexplained LVH (interventricular septum or left ventricular wall thickness $\geq 13 \mathrm{~mm}$ ) had clinically unsuspected Fabry disease (42). In a second retrospective analysis of 153 male patients attending a referral clinic for patients with HCM, the prevalence of Fabry disease based on plasma $\alpha$-galactosidase A activity was $4 \%$, rising to $6,3 \%$ in those first diagnosed over 40 years of age (43). Ommen et al in 2003 examined consecutive HCM patients (44 men) who underwent septal myectomy. Transmission electron microscopy of myectomy tissue did not show any histological abnormalities indicating Fabry disease (44), which may suggest that asymmetrical hypertrophy, indicating surgical myectomy, is rare in Fabry disease. Chimenti et al in 2004 examined 96 (34 women, 62 men) HCM patients, in whom biventricular endomyocardial biopsy and measurement of leucocyte $\alpha$-galactosidase A activity was performed. The prevalence of Fabry disease was found to be $6,2 \%$ in men and $11,8 \%$ in women (45). The limitation of the study included that the screening was based on myocardial biopsies, which was selective for infiltrative diseases. Arad et al screened 75 (30 women, 45 men) HCM patients with molecular genetic methods. No GLA mutation was found during the screening (16). Morita et al identified 50 patients (18\% women) out of 1862 subjects with echocardiographic evidence of unexplained LVH (maximal LV wall thickness $>13 \mathrm{~mm}$ ). Molecular genetic analysis was performed, which resulted in a $2 \%$ prevalence for Fabry disease (46). Monserrat et al performed the screening of $\alpha$ galactosidase A activity in the plasma of 508 consecutive unrelated patients (328 men, 180 women) with HCM from three regional centers in Spain and demonstrated 
Table 5. Summary of previous studies examining the prevalence of Fabry disease in patients with HCM

\begin{tabular}{|c|c|c|c|c|}
\hline Authors & Year & Screened population & Screening method & Prevalence \\
\hline Nakao et al (6) & 1995 & $\begin{array}{l}230 \text { male patients with echocardiographic evidence of LVH } \\
\text { (septum or left ventricular posterior wall thickness } \geq 13 \mathrm{~mm} \text { ) } \\
\text { from cohort of } 1603 \text { male subjects }\end{array}$ & Plasma $\alpha$-galactosidase A activity & $3.0 \%$ \\
\hline Sachdev et al (7) & 2002 & $\begin{array}{l}79 \text { consecutive men with HCM (unexplained LVH with a } \\
\text { MLVWT } \geq 13 \mathrm{~mm} \text { ), first diagnosed } \geq 40 \text { years of age and } 74 \\
\text { HCM men first diagnosed }<40 \text { years of age }\end{array}$ & Plasma $\alpha$-galactosidase A activity & $\begin{array}{l}6.3 \% \text { in patients diagnosed } \\
\geq 40 \text { years } 1.4 \% \text { in patients } \\
\text { diagnosed }<40 \text { years }\end{array}$ \\
\hline Ommen et al (8) & 2003 & $\begin{array}{l}100 \text { consecutive HCM patients (44 men) who underwent septal } \\
\text { myectomy }\end{array}$ & $\begin{array}{l}\text { Transmission electron microscopy } \\
\text { of myectomy tissue }\end{array}$ & $0 \%$ \\
\hline Chimenti et al (9) & 2004 & $\begin{array}{l}34 \text { consecutive female patients with HCM (unexplained LVH } \\
\text { with a MLVWT } \geq 13 \mathrm{~mm} \text { ) }\end{array}$ & $\begin{array}{l}\text { Biventricular endomyocardial } \\
\text { biopsy and leucocyte } \alpha \text { - } \\
\text { galactosidase A activity }\end{array}$ & $11.8 \%$ \\
\hline Arad et al (10) & 2005 & $\begin{array}{l}75 \text { consecutive patients with HCM ( } 30 \text { women, } 45 \text { men) } \\
\text { (unexplained LVH with MLVWT } \geq 13 \mathrm{~mm} \text { ) }\end{array}$ & Genetic analysis & $0 \%$ \\
\hline Morita $\mathrm{H}$ et al (11) & 2006 & $\begin{array}{l}50 \text { patients (18\% women) with echocardiographic evidence of } \\
\text { unexplained LVH (MLVWT }>13 \mathrm{~mm} \text { ) from a cohort of } 1862 \\
\text { subjects }\end{array}$ & Genetic analysis & $2 \%$ \\
\hline Monserrat et al (13) & 2007 & $\begin{array}{l}508 \text { consecutive patients ( } 328 \text { men, } 180 \text { women) with HCM } \\
\text { diagnosed according to the WHO/ESC criteria }\end{array}$ & Plasma $\alpha$-galactosidase A activity & $1 \%$ \\
\hline Hagege et al (12) & 2011 & $\begin{array}{l}392 \text { patients with HCM (unexplained LVH with MLVWT } \geq 15 \\
\text { mm) ( } 278 \text { men) aged } 18-79 \text { years }\end{array}$ & $\begin{array}{l}\alpha \text {-galactosidase A assay on dried } \\
\text { blood spot using a filter paper test }\end{array}$ & $1 \%$ \\
\hline Elliot et al (14) & 2011 & $\begin{array}{l}1386 \text { patients with HCM ( } 885 \text { men, unexplained LVH with a } \\
\text { MLVWT } \geq 15 \mathrm{~mm} \text { ) }\end{array}$ & Genetic analysis & $0.5 \%$ \\
\hline
\end{tabular}

LVH: left ventricular hypertrophy; HCM: hypertrophic cardiomyopathy, MLVWT: maximum left ventricular wall thickness, ESC: European Society of Cardiology 
low $\alpha$-galactosidase A levels in 15 patients (2.9\%). However, subsequent genetic analysis demonstrated disease causing mutations in only $0.6 \%$ of men and between $1.2 \%$ and $2.4 \%$ (including two with an intronic deletion) of women (47). Hagège et al examined the prevalence of Fabry disease in patients with LVH of $13 \mathrm{~mm}$ or greater using an $\alpha$ galactosidase A assay (48) and the overall prevalence in men was found to be $1.5 \%$. No female heterozygotes were detected, but this method has a low sensitivity in women, and no systematic genetic sequencing was performed. So far, Elliott et al performed the largest similar screening in 2011, who performed molecular genetic mutation analysis on 1386 (885 men, unexplained LVH with a MLVWT $\geq 15 \mathrm{~mm}$ ) HCM patients. Seven GLA mutations were identified in the population, which gave a $0,5 \%$ prevalence (49).

In our present work we carried out screening for Fabry disease in patients, who had cardiac, but at the same time other organ manifestations, which raised the suspicion of Fabry disease. We identified 4 GLA mutations in 4 patients (19\%) out of 21 patients we screened (4 women, average age $49 \pm 15$ ). The prevalence of GLA mutations in Fabry disease considering the subgroup of patients with left ventricular hypertrophy or hypertrophic cardiomyopathy was $17 \%$. The explanation for the much higher prevalence in the present study as compared to previous ones is that we selected patients not just with isolated cardiac involvement, but with signs of other organ manifestations (neurological, nephrological, dermatological, etc.). These data underlines the fact, that in the case of a "typical" HCM the possible prevalenece of Fabry disease is low (approx. 0.5-1\%), but if other possible organ manifestation is present in addition to HCM, the chance for the presence of Fabry disease is significantly higher.

One mutation out of four GLA mutations we identified is an already known mutation, while the other three are novel gene mutations. The GLA p.Glu358Lys mutation was earlier identified in a Japanese male patient (50), who had episodic pain in the extremities and angiokeratoma on his chest and also on both palms from the age of 10 years. His brother also had the same symptoms from the age of 12 years. The assumed causative effect of the p.Glu358Lys mutation is the damage of the protein 'folding'.

The reported GLA p.Ile239Met mutation is a novel mutation, although an amino acid change at this position has already been described as disease-causing for Fabry disease by Kotanko in 2004 (c.716T>C, p.Ile239Thr, HGMD ID: CM044637) (51). The mutation was identified in a male patient, who experienced recurrent fever, pain, lymphadenopathy and acroparesthesia in early childhood. Later on shrunken right kidney and stage 4 chronic kidney disease were diagnosed, also acute hearing loss, dizziness, headache, dysphasia and 
dysarthria developed. Multiple cerebral lesions detected by magnetic resonance imaging were related to stage 3 hypertension. Fabry disease was diagnosed during the course of the screening study. Reexamination of the kidney biopsy material by electron microscopy showed typical signs of Fabry disease that were previously not identified by light microscopy. The patient also had cornea verticillata and mild left ventricular hypertrophy. His 48-year-old mother (normal GLA activity) and his two daughters (aged 3 and 8 years; decreased GLA activity in both) exhibited the same mutation. These three female relatives do not show clinical signs and symptoms of Fabry disease.

On the basis of the current recommendations of the American College of Medical Genetics and Genomics (ACMG) and the Association for Molecular Pathology (AMP) there are multiple lines of evidences to characterise the p.Ile239Met mutation as 'pathogenic' for Fabry disease. First and most important, the observation of the markedly decreased GLA enzyme level in the affected male carrier and the increased lyso-Gb3 levels in all the mutation carriers provides evidence for the damaging consequences of the mutation on the gene product (PS3, strong evidence of pathogenicity). Second, the mutation is absent from controls in Exome Sequencing Project, 1000 Genomes Project, or Exome Aggregation Consortium (PM2, moderately strong evidence of pathogenicity). Third, the mutation is a novel missense change at an amino acid residue where a different missense change (p.Ile239Thr, see above) determined to be pathogenic has been seen before (PM5, moderately strong evidence of pathogenicity). Fourth, cosegregation with disease in multiple affected family members in the GLA gene, definitively known to cause the disease, has been shown (PP1, supporting evidence of pathogenicity). It is of note, that the $>2$ LOD score we obtained by linkage analysis in the family is highly suggestive, although not conclusive in itself, for the causative role of the variant, as it provides substantial evidence for the cosegregation of the mutation with the disease phenotype. Fifth, multiple lines of computational evidence support a deleterious effect on the gene or gene product (PP3, supporting evidence of pathogenicity). By applying the rules of the ACMG/AMP guideline for combining criteria to classify sequence variants as 'pathogenic' (1 Strong AND 2 Moderate AND $\geq 2$ Supporting) the p.Ile239Met GLA variant that we have identified completely satisfy the criteria of being 'pathogenic'.

The third detected GLA mutation, p.Tyr397Stop, is a previously unpublished, novel mutation. The mutation presumably caused the interruption of the reading frame, consequently a shorter, truncated protein can be produced, which may not function 
properly. The biomarker of Fabry disease, the lyso-Gb3 level was mildly increased in the mutation carrier patient.

The fourth identified GLA variant, c.548-57_-56dupTA, is a previously unpublished heterozygous variant in intron 3 of GLA gene. The effect of the variant is neutral, based on a prediction analysis, because of the suspected indifferent effect on the mRNA 'splicing'. The prediction analysis of the variant indicated the variant to be a 'variant of unknown significance' (VUS), although the histological examination of the patient confirmed the characteristics of Fabry disease. Although recommendations suggest to clarify the significance of these variants by family screening or functional analysis (52-54), unfortunately this was not possible in our case.

As a specific enzyme replacement therapy (ERT) for Fabry disease is available, early diagnosis of a real Fabry patient is of great importance to initiate the otherwise invasive and expensive ERT. Both agalsidase-alpha and agalsidase-beta therapy can prolong disease manifestation, slow down the disease progression, and improve life quality of patients. In a recent study it was shown, that the progression of left ventricular hypertrophy was successfully slowed down on agalsidase-alpha therapy in Fabry patients during 10 years follow up (55).

\subsection{Identification of $T T R$ mutations in patients with transthyretin amyloidosis}

According to the Human Gene Mutation Database, more than 100 mutations are known to affect the TTR gene. Different TTR gene mutations will lead to different phenotypes with neuropathic, cardiomyopathic, nephropathic, and ocular forms (30). Typical forms may be accumulated in specific populations. The clinical manifestation can be highly variable even in the case of the same genetic background: the disease process may remain nearly asymptomatic or it may be severe, may begin at older or at a younger age. Point (missense) mutations are the most typical mutations affecting the gene, but even small deletions and small indel mutations has been also described. In rare cases a „new” ('de novo') mutation can occur, which does not appear in any other family member. Mutations in the TTR gene can lead to conformational changes of the encoded protein, which is essential for amyloid fiber formation.

The p.His108Arg TTR mutation, we identified in Patient A has already been described previously in a Swedish family (56). They reported a 65-years-old index patient with biventricular heart failure, with diffusely thickened ventricular walls (IVS: $21 \mathrm{~mm}$ ), left 
ventricular hypokinesis, and elevated NT-pro-BNP levels. Besides cardiac involvement, gastrointestinal and polyneuropathic symptoms were also present. The patient died at the age of 70 years after 5 years of follow-up. Six additional affected family member were confirmed during family screening, five had disease manifestation in the form of cardiomyopathy, which appeared dominantly at later ages ( $>50$ years). Genealogical study showed that they all have common ancestors 9-10 generations back into the 17th century originating from Dalarna (Dalecarlia) in Sweden. So this mutation could be designated as a 'founder' mutation in Sweden (57).

Histidine at position 88 (His88) is an amino acid in TTR that is important for the stability of the TTR tetramer. A large hydrogen-bond network is formed by Thr75, Trp79, His88, Ser112, Pro113 and three water molecules $(58,59)$. In addition, His88 also forms a hydrogen-bond network with Thr118 of another TTR subunit. Through these two networks His88 is associated with both the dimer-dimer interface as well as the monomer-monomer interface in the TTR tetramer. His88 is also located in the EF-loop (amino acids 95-101) in TTR. Mutations within the EF-helix (amino acids 102-110, where 108His is located) and the EF-loop are disposed to TTR monomer aggregation into fibrils (60-63). Several amino acid residues, including His88, in this region are highly affected by conformational changes at acidic $\mathrm{pH}$. Histidine is a basic amino acid characterized by its imidazole group, which makes it the only amino acid that functions in both acid and base catalysis. The imidazole side chain of histidine is a common coordinating ligand in metalloproteins, and His88 forms a $\mathrm{Zn}^{2+}$ binding site with His90, Glu92 and a water molecule (64), which enables TTR to function as a metallopeptidase $(65,66)$. A mutation that changes His 88 should have a profound impact on both TTR $\mathrm{Zn}^{2+}$ binding properties and monomermonomer binding, theoretically making it highly amyloidogenic.

The p.Gly26Ser TTR gene variant identified in Patient B is not a rare variant worldwide, according to the literature. The allele frequency of p.Gly26Ser is 6-12\% in an average Caucasian population, 4\% in North American Ashkenazi Jews, 7\% in North American non-Jews, 6\% in Portuguese and 1\% African-American population (67). Based on these evidences, the variant is considered to be a benign, non-amyloidogenic TTR variant (68). Considering the accumulation of the TTR demonstrated by immunohistochemistry assay and the lack of TTR gene mutation, the infiltration in the heart of Patient B corresponds to wild-type transthyretin and the case corresponds to senile amyloidosis. 


\section{SUMMARY AND CONCLUSIONS}

\section{We identified two novel LAMP2 gene mutations in patients with Danon disease}

By screening two patients with extreme concentric LV hypertrophy, pre-excitation on the ECG, muscle dystrophy/CK rise, and variable mental retardation, we identified two families with two novel LAMP2 gene mutations, p.Trp321Stop and p.Pro324fs $+24 \mathrm{X}$, causing Danon disease. Both mutations were predicted to lead to a truncated LAMP-2 protein that presumably lacks the transmembrane and cytoplasmic domains. We observed a markedly malignant phenotype in both families characterised by a large proportion of disease related death.

\section{We identified known and novel $G L A$ gene mutations in patients with Fabry disease}

Screening patients with suspected Fabry disease, based on the presence of cardiac and extracardiac manifestations, we identified known (p.Glu358Lys) and novel (p.Ile239Met, p.Tyr397Stop, c.548-57_-56dupTA) GLA gene mutations. In particular, we described a family with a novel p.Ile239Met GLA gene mutation where cardiac involvement in the form of hypertrophic cardiomyopathy, LV hypertrophy and ECG changes was the most common manifestation of the disease and severe renal failure occurred in one family member. We concluded that the p.Ile239Met GLA mutation is a pathogenic mutation for Fabry disease and obviously associated with a late onset and predominantly a cardiac variant of the disease.

3. We established a $17 \%$ prevalence rate of Fabry disease in patients with hypertrophic cardiomyopathy or left ventricular hypertrophy manifesting additional symptoms, indicating multi-organ involvement

Screening patients with suspected Fabry disease, based on cardiac involvement (mostly in the form of hypertrophic cardiomyopathy or left ventricular hypertrophy) and additional signs of non-cardiac manifestation (neurological, renal, ocular or dermatological symptoms) we found a $17 \%$ prevalence of GLA mutations indicating Fabry disease. Our results suggest, that in case of unexplained left ventricular hypertrophy or hypertrophic cardiomyopathy and additional suspicious organ manifestations the possibility of Fabry disease should be higher. 


\section{We identified TTR gene mutations in patients with TTR amyloidosis}

Two non-synonymous transthyretin gene variants were identified in two patients with hypertrophic cardiomyopathy phenotype. In the first case a previously published, malignant missense mutation (p.His108Arg) was found in the index patient and also in his mother, therefore the case corresponded to familial transthyretin amyloidosis. Wild type transthyretin deposition was detected in the second case, thus in this case the patient had senile systemic amyloidosis. 


\section{ACKNOWLEDGEMENTS}

Firstly, I would like to express my sincere gratitude to my supervisor Dr. Robert Sepp for the continuous support of my $\mathrm{PhD}$ study and related research, for his patience, motivation, and immense knowledge. His guidance helped me in all the time of research and writing of this thesis.

My sincere thanks also goes to Professor Tamás Forster, and Professor Miklós Csanády, current and former Head of Department, who provided me an opportunity to join their team as a $\mathrm{PhD}$ student, and who gave access to the laboratory and research facilities. Without they precious support it would not be possible to conduct this research.

I thank my fellow labmates for the stimulating discussions, for the sleepless nights we were working together before deadlines, and for all the fun we have had during my $\mathrm{PhD}$ years. In particular, I am especially grateful to Molnár Jánosné Klári for enlightening me the first glance of laboratory work.

Last but not the least, I would like to thank my family, my parents and my friends for supporting me spiritually throughout writing this thesis and my life in general. 


\section{REFERENCES}

1 Elliott P, McKenna WJ. Hypertrophic cardiomyopathy. Lancet 2004;363:1881-91.

2. Elliott PM, Anastasakis A, Borger MA et al. 2014 ESC Guidelines on diagnosis and management of hypertrophic cardiomyopathy: the Task Force for the Diagnosis and Management of Hypertrophic Cardiomyopathy of the European Society of Cardiology (ESC). Eur Heart J 2014;35:2733-79.

3. Gersh BJ, Maron BJ, Bonow RO et al. 2011 ACCF/AHA Guideline for the Diagnosis and Treatment of Hypertrophic Cardiomyopathy: a report of the American College of Cardiology Foundation/American Heart Association Task Force on Practice Guidelines. Developed in collaboration with the American Association for Thoracic Surgery, American Society of Echocardiography, American Society of Nuclear Cardiology, Heart Failure Society of America, Heart Rhythm Society, Society for Cardiovascular Angiography and Interventions, and Society of Thoracic Surgeons. J Am Coll Cardiol 2011;58:e212-60.

4. Writing Committee Members, Maron BJ, McKenna WJ et al. American College of Cardiology/European Society of Cardiology Clinical Expert Consensus Document on Hypertrophic Cardiomyopathy: A report of the American College of Cardiology Foundation Task Force on Clinical Expert Consensus Documents and the European Society of Cardiology Committee for Practice Guidelines 10.1016/S0195668X(03)00479-2. Eur Heart J 2003;24:1965-1991.

5. Maron B, Gardin J, Flack J, Gidding S, Kurosaki T, Bild D. Prevalence of hypertrophic cardiomyopathy in a general population of young adults. Echocardiographic analysis of 4111 subjects in the CARDIA Study. Coronary Artery Risk Development in (Young) Adults. Circulation 1995;92:785-9.

6. Ho CY, Charron P, Richard P, Girolami F, Van Spaendonck-Zwarts KY, Pinto Y. Genetic advances in sarcomeric cardiomyopathies: state of the art. Cardiovasc Res 2015; 105:397-408.

7. Alcalai R, Seidman JG, Seidman CE. Genetic basis of hypertrophic cardiomyopathy: from bench to the clinics. J Cardiovasc Electrophysiol 2008;19:104-10.

8. Geisterfer-Lowrance AAT, Kass S, Tanigawa G et al. A molecular basis for familial hypertrophic cardiomyopathy: a beta cardiac myosin heavy chain gene missense mutation. Cell 1990;62:999-1006.

9. Thierfelder L, Watkins $\mathrm{H}$, MacRae $\mathrm{C}$ et al. Alpha-tropomyosin and cardiac troponin $\mathrm{T}$ mutations cause familial hypertrophic cardiomyopathy: a disease of the sarcomere. Cell 1994;77:701-12.

10. Bonne $\mathrm{G}$, Carrier L, Bercovici $\mathrm{J}$ et al. Cardiac myosin binding protein-C gene splice acceptor site mutation is associated with familial hypertrophic cardiomyopathy. Nat Genet 1995;11:438-40.

11. Watkins H, Conner D, Thierfelder L et al. Mutations in the cardiac myosin binding protein-C gene on chromosome 11 cause familial hypertrophic cardiomyopathy. Nat Genet 1995;11:434-7.

12. Kimura A, Harada H, Park J-E et al. Mutations in the troponin I gene associated with hypertrophic cardiomyopathy. Nature Gen 1997;16:379-82.

13. Poetter K, Jiang $\mathrm{H}$, Hassanzadeh $\mathrm{S}$ et al. Mutations in either the essential or regulatory light chains of myosin are associated with a rare myopathy in human heart and skeletal muscle. Nat Genet 1996;13:63-9.

14. Mogensen J, Klausen I, Pedersen A et al. Alpha-cadiac actin is a novel disease gene in familial hypertrophic cardiomyopathy. J Clin Invest 1999;103:R39-R43. 
15. Satoh M, Takahashi M, Sakamoto T, Hiroe M, Marumo F, Kimura A. Structural analysis of the titin gene in hypertrophic cardiomyopathy: identification of a novel disease gene. Biochem Biophys Res Commun 1999;262:411-7.

16. Arad M, Maron BJ, Gorham JM et al. Glycogen storage diseases presenting as hypertrophic cardiomyopathy. N Engl J Med 2005;352:362-72.

17. Danon MJ, Oh SJ, DiMauro S, Manaligod JR, Eastwood A, Naidu S, et al. Lysosomal glycogen storage disease with normal acid maltase. Neurology. 1981;31:51-7.

18. Nishino I, Fu J, Tanji K, Yamada T, Shimojo S, Koori T, et al. Primary LAMP-2 deficiency causes X-linked vacuolar cardiomyopathy and myopathy (Danon disease). Nature. 2000;406:906-10.

19. Arad M, Maron BJ, Gorham JM, Johnson WH, Jr., Saul JP, Perez-Atayde AR, et al. Glycogen storage diseases presenting as hypertrophic cardiomyopathy. N Engl J Med. 2005;352:362-72.

20. Sugie K, Koori T, Yamamoto A, Ogawa M, Hirano M, Inoue K, et al. Characterization of Danon disease in a male patient and his affected mother. Neuromuscul Disord. 2003;13:708-11.

21. Fukuda M. Biogenesis of the lysosomal membrane. Sub-cellular biochemistry. 1994;22:199-230.

22. Gough NR, Fambrough DM. Different steady state subcellular distributions of the three splice variants of lysosome-associated membrane protein LAMP-2 are determined largely by the $\mathrm{COOH}$-terminal amino acid residue. The Journal of cell biology. 1997;137:1161-9.

23. Eskelinen EL, Cuervo AM, Taylor MR, Nishino I, Blum JS, Dice JF, et al. Unifying nomenclature for the isoforms of the lysosomal membrane protein LAMP-2. Traffic. 2005;6:1058-61.

24. Germain DP. Fabry disease. Orphanet J Rare Dis. 2010;5:30.

25. Germain DP, Benistan K, Angelova L. X-linked inheritance and its implication in the diagnosis and management of female patients in Fabry disease. Rev Med Interne. 2010;31 Suppl 2:S209-213.

26. Abbas A. Diseases of immunity: amyloidosis. In: Kumar V, Abbas AK, Fausto N, eds. Pathologic Basis of Disease. Philadelphia, PA: Elsevier Saunders; 2005:258264.

27. Ruberg FL, Berk JL. Transthyretin (TTR) cardiac amyloidosis. Circulation. 2012;126:1286-1300.

28. Esplin BL, Gertz MA. Current trends in diagnosis and management of cardiac amyloidosis. Curr Probl Cardiol. 2013;38:53-96.

29. Sharma N, Howlett J. Current state of cardiac amyloidosis. Curr Opin Cardiol. 2013;28:242-248.

30. Ando Y, Coelho T, Berk JL, et al. Guideline of transthyretin-related hereditary amyloidosis for clinicians. Orphanet J Rare Dis. 2013;8:31.

31. Yang Z, McMahon CJ, Smith LR, Bersola J, Adesina AM, Breinholt JP, et al. Danon disease as an underrecognized cause of hypertrophic cardiomyopathy in children. Circulation. 2005;112:1612-7.

32. Charron P, Villard E, Sebillon P, Laforet P, Maisonobe T, Duboscq-Bidot L, et al. Danon's disease as a cause of hypertrophic cardiomyopathy: a systematic survey. Heart. 2004;90:842-6.

33. Echaniz-Laguna A, Mohr M, Epailly E, Nishino I, Charron P, Richard P, et al. Novel Lamp-2 gene mutation and successful treatment with heart transplantation in a large family with Danon disease. Muscle Nerve. 2006;33:393-7. 
34. Taylor MR, Ku L, Slavov D, Cavanaugh J, Boucek M, Zhu X, et al. Danon disease presenting with dilated cardiomyopathy and a complex phenotype. J Hum Genet. 2007;52:830-5.

35. Dougu N, Joho S, Shan L, Shida T, Matsuki A, Uese K, et al. Novel LAMP-2 mutation in a family with Danon disease presenting with hypertrophic cardiomyopathy. Circ J. 2009;73:376-80.

36. Boucek D, Jirikowic J, Taylor M. Natural history of Danon disease. Genet Med. 2011;13:563-8.

37. Maron BJ, Roberts WC, Arad M, Haas TS, Spirito P, Wright GB, et al. Clinical outcome and phenotypic expression in LAMP2 cardiomyopathy. JAMA. 2009;301:1253-9.

38. Yang Z, Funke BH, Cripe LH, Vick GW, 3rd, Mancini-Dinardo D, Pena LS, et al. LAMP2 microdeletions in patients with Danon disease. Circ Cardiovasc Genet. 2010;3:129-37.

39. Hsu JC, Tanel RE, Lee BK, Scheinman MM, Badhwar N, Lee RJ, et al. Differences in accessory pathway location by sex and race. Heart rhythm : the official journal of the Heart Rhythm Society. 2010;7:52-6.

40. Fanin M, Nascimbeni AC, Fulizio L, Spinazzi M, Melacini P, Angelini C. Generalized lysosome-associated membrane protein-2 defect explains multisystem clinical involvement and allows leukocyte diagnostic screening in Danon disease. Am J Pathol. 2006;168:1309-20.

41. Lacoste-Collin L, Garcia V, Uro-Coste E, Arne-Bes MC, Durand D, Levade T, et al. Danon's disease (X-linked vacuolar cardiomyopathy and myopathy): a case with a novel Lamp-2 gene mutation. Neuromuscul Disord. 2002;12:882-5.

42. Nakao S, Takenaka T, Maeda M, et al. An atypical variant of Fabry's disease in men with left ventricular hypertrophy. N Engl J Med. 1995;333:288-293.

43. Sachdev B, Takenaka T, Teraguchi H, et al. Prevalence of Anderson-Fabry disease in male patients with late onset hypertrophic cardiomyopathy. Circulation. 2002;105:1407-1411.

44. Ommen SR, Nishimura RA, Edwards WD. Fabry disease: a mimic for obstructive hypertrophic cardiomyopathy? Heart. 2003;89:929-930.

45. Chimenti C, Pieroni M, Morgante E, et al. Prevalence of Fabry disease in female patients with late-onset hypertrophic cardiomyopathy. Circulation. 2004;110:10471053.

46. Morita H, Larson MG, Barr SC, et al. Single-gene mutations and increased left ventricular wall thickness in the community: the Framingham Heart Study. Circulation. 2006;113:2697-2705.

47. Monserrat L, Gimeno-Blanes JR, Marin F, et al. Prevalence of fabry disease in a cohort of 508 unrelated patients with hypertrophic cardiomyopathy. J Am Coll Cardiol. 2007;50:2399-2403.

48. Hagege AA, Caudron E, Damy T, et al. Screening patients with hypertrophic cardiomyopathy for Fabry disease using a filter-paper test: the FOCUS study. Heart. 2011;97:131-136.

49. Elliott P, Baker R, Pasquale F, et al. Prevalence of Anderson-Fabry disease in patients with hypertrophic cardiomyopathy: the European Anderson-Fabry Disease survey. Heart. 2011;97:1957-1960.

50. Miyazaki T, Kajita M, Ohmori S, et al. A novel mutation (E358K) in the alphagalactosidase A gene detected in a Japanese family with Fabry disease. Hum Mutat. 1998;Suppl 1:S139-140. 
51. Kotanko P, Kramar R, Devrnja D, et al. Results of a nationwide screening for Anderson-Fabry disease among dialysis patients. J Am Soc Nephrol. 2004;15:13231329.

52. Richards S, Aziz N, Bale S, et al. Standards and guidelines for the interpretation of sequence variants: a joint consensus recommendation of the American College of Medical Genetics and Genomics and the Association for Molecular Pathology. Genet Med. 2015;17:405-424.

53. Smid BE, Hollak CE, Poorthuis BJ, et al. Diagnostic dilemmas in Fabry disease: a case series study on GLA mutations of unknown clinical significance. Clin Genet. 2015;88:161-166.

54. Smid BE, van der Tol L, Cecchi F, et al. Uncertain diagnosis of Fabry disease: consensus recommendation on diagnosis in adults with left ventricular hypertrophy and genetic variants of unknown significance. Int J Cardiol. 2014;177:400-408.

55. Kampmann C, Perrin A, Beck M. Effectiveness of agalsidase alfa enzyme replacement in Fabry disease: cardiac outcomes after 10 years' treatment. Orphanet J Rare Dis. 2015;10:125.

56. Holmgren G, Hellman U, Anan I, et al. Cardiomyopathy in Swedish patients with the Gly53Glu and His88Arg transthyretin variants. Amyloid. 2005;12:184-188.

57. Hellman U, Lundgren HE, Westermark P, et al. A genealogical and clinical study of the phenotypical variation within the Swedish transthyretin His88Arg (p. His108Arg) amyloidosis family. Eur J Med Genet. 2015;58:211-215.

58. Mizuguchi M, Yokoyama T, Nabeshima Y, et al. Quaternary structure, aggregation and cytotoxicity of transthyretin. Amyloid. 2012;19 Suppl 1:5-7.

59. Yokoyama T, Mizuguchi M, Nabeshima $\mathrm{Y}$, et al. Hydrogen-bond network and $\mathrm{pH}$ sensitivity in transthyretin: Neutron crystal structure of human transthyretin. $J$ Struct Biol. 2012;177:283-290.

60. Booth DR, Stangou A, Williams RS, et al. Transthyretin Ile84Thr is associated with familial amyloid polyneuropathy. Hum Mutat. 2000;16:447.

61. Liepnieks JJ, Wilson DL, Benson MD. Biochemical characterization of vitreous and cardiac amyloid in Ile84Ser transthyretin amyloidosis. Amyloid. 2006;13:170177.

62. Nakamura M, Hamidi Asl K, Benson MD. A novel variant of transthyretin (Glu89Lys) associated with familial amyloidotic polyneuropathy. Amyloid. 2000;7:46-50.

63. Redondo C, Damas AM, Olofsson A, et al. Search for intermediate structures in transthyretin fibrillogenesis: soluble tetrameric Tyr78Phe TTR expresses a specific epitope present only in amyloid fibrils. J Mol Biol. 2000;304:461-470.

64. Palmieri L de C, Lima LM, Freire JB, et al. Novel Zn2+-binding sites in human transthyretin: implications for amyloidogenesis and retinol-binding protein recognition. J Biol Chem. 2010;285:31731-31741.

65. Gouvea IE, Kondo MY, Assis DM, et al. Studies on the peptidase activity of transthyretin (TTR). Biochimie. 2013;95:215-223.

66. Liz MA, Leite SC, Juliano L, et al. Transthyretin is a metallopeptidase with an inducible active site. Biochem J. 2012;443:769-778.

67. Jacobson DR, Alves IL, Saraiva MJ, et al. Transthyretin Ser 6 gene frequency in individuals without amyloidosis. Hum Genet. 1995;95:308-312.

68. Connors LH, Lim A, Prokaeva T, et al. Tabulation of human transthyretin (TTR) variants, 2003. Amyloid. 2003;10:160-184 